\title{
A review of clinical trials of chemotherapy for pancreatic cancer
}

\author{
Hui Zhu, Xinwei Wang, Xiagang Luo, Xiang Yu and Chunzhao Yu* \\ Department of Surgery, Second Affiliated Hospital, Nanjing Medical University, Nanjing, P. R. China. \\ Accepted 19 October, 2012
}

\begin{abstract}
Chemotherapy is playing an important role in treating pancreatic cancer, either when used alone or when combined with surgery and radiotherapy. We summarized 80 eligible clinical trials published from January in 2006 to June in 2011 and discussed the future development of chemotherapy in the treatment of pancreatic cancer. All the clinical trials were divided into 5 groups: single-agent regimen (14 trials), binary combination (27 trials), triple or more combination (13 trials), neoadjuvant/preoperative chemotherapy (4 trials), and targeted therapy (22 trials). Gemcitabine used alone was confirmed effective in 5 trials, while fixed-dose-rate gemcitabine showed apparent toxicities. In 4 trials, oral S-1 seemed feasible and convenient as a second-line agent. Explorations of irinotecan and paclitaxel loaded polymeric micelle as single agents also got positive outcomes. Many trials focused on the gemcitabine-based combinations with drugs like cisplatin, S-1, oxaliplatin, glufosfamide, etc., and some got positive results. Due to the occurrences of gemcitabine-resistance or even 5-fluorouracil-resistance, second-line combinations have become important and some have shown considerable value. Apart from the binary combination, three or more drugs used together, like FOLFOX (5-fluorouracil, leucovorin, and oxaliplatin) and FOLFIRI (5-fluorouracil, leucovorin, and irinotecan) also exhibited promising activity. A new method called neoadjuvant therapy (treating patients with drugs before surgery) was investigated in 4 trials with encouraging outcomes. In addition, some sites related to tumor cell proliferation and metastasis, such as growth factor receptor, CTLA-4 (CD152), the mammalian target of rapamycin, cyclooxygenase-2, cholecystokinin-2 receptor, leukotriene B4 receptor, peroxisome proliferator-activated receptor gamma and proto-oncogene, have been explored in some clinical trials and are worth further researches.
\end{abstract}

Key words: Chemotherapy, pancreatic cancer, clinical trials.

\section{INTRODUCTION}

Nowadays, pancreatic cancer has become the fourth most common cause of cancer-related death in adults in China and United States (Li et al., 2004). The annual incidence rate of pancreatic cancer is almost identical to the mortality rate (Muhammad, 2008). Although, a lot of efforts have been made, still the current state of pancreatic cancer treatment is unsatisfactory. Merely depending on the improvement of surgery cannot change the dimmed picture. In China, the incidence rate of this malignancy has increased about 6 times since 1970s (Lu

${ }^{*}$ Corresponding author. E-mail: chunzhaoyu@hotmail.com. Tel: 025-58509832. Fax: 025-58509994.
Xing, 1997). About $80 \%$ patients have lost chances of operations, because the cancer has become advanced or metastasized when diagnosed (Kelly and Benjamin, 1995). An epidemiological research indicated that the overall resection rate was less than 3\% (Bramhall et al., 1995). Even after resections, 5 -year survival remains only 7 to $24 \%$, and median survival is only approximately 1 year in most series, implying that surgery alone is inadequate (Nitecki et al., 1995). To argument surgery, chemotherapy plays an important role and has been investigated by many researchers. Gemcitabine, which has been shown to result in improved clinical benefit and slightly longer mean survival time, becomes the first-line chemotherapy for pancreatic cancer (Kulke, 2003). However, published results indicated that prolonged 
exposure to gemcitabine leads to acquired resistance in some pancreatic cancer cells, which is also a major cause of treatment failure (Blaszkowsky, 1998). In the past, about 5 years ago, many clinical trials aiming at overcoming the resistance and exploring new approaches to the treatment of pancreatic cancer, have been conducted, using different kinds of chemotherapy drugs.

\section{METHODOLOGY}

A PubMed search of clinical trials from January in 2006 to June in 2011 was carried out, using the search terms "pancreatic, cancer, chemotherapy" in the "AND" relationship. All studies related to radiotherapy, getting absolute negative results or phase I trial (focusing on revising dosage) were excluded because of their few connections on the substance. At the end, 80 trials were determined and other relevant studies were included by a further research of some important references. All the 80 investigations were divided into 5 groups: (1) single-agent regimen (114 trials, Table 1); (2) binary combination (27 trials, Table 2); (3) triple or more combination (13 trials, Table 3); (4) neoadjuvant/preoperative chemotherapy (4 trials, Table 4); (5) targeted therapy (22 trials, Table 5).

\section{RESULTS}

\section{Single-agent regimen}

\section{Gemcitabine}

Gemcitabine, as a pyrimidine antimetabolite (Heinemann et al., 1988) has an effective activity in many solid tumors. Identifying its better efficacy than 5-fluorouracil in 1997 (Burris et al., 1997), single-agent gemcitabine has been recommended as the first choice of treating pancreatic cancer (Arshad et al., 2011). A randomized controlled trial (Oettle et al., 2007) supported the use of gemcitabine as adjuvant chemotherapy after curativeintent resection. In the trial, 179 patients received 6 cycles of gemcitabine on day 1,8 , and 15 every 4 weeks and 175 patients received only observation. Median disease-free survival in the gemcitabine group and the observation group was 13.4 months $(95 \%$ confidence interval, 11.4 to 15.3$)$ and 6.9 months $(95 \%$ confidence interval, 6.1 to $7.8 ; P<0.001$, log-rank), respectively. Estimated disease-free survival at 3 and 5 years of the gemcitabine group was 23.5 and $16.5 \%$, compared with 7.5 and $5.5 \%$ in the observation group. The rate of recurrent disease was lower in the treatment group (74 versus $92 \%$ ). However, no statistical difference was shown in the overall survival between the two groups.

An analogous trial from Japanese (58 patients in the gemcitabine group and 60 patients in the surgery-only group) was reported by Ueno et al. (2009). Median disease-free survival was longer in the gemcitabine group (11.4 versus 5.0 months; hazard ratio $=0.77,95 \%$ confidence interval: 0.51 to $1.14 ; P=0.19$ ), while the overall survival did not show significant differences, which was concurrent with the results of the former trial. Frequent but the most transient hematological toxicities occurred in the gemcitabine group.

To further evaluate the efficacy and safety of gemcitabine, Ishii et al. (2010) reported a study with 50 locally advanced pancreatic cancer patients enrolled from 2006 to 2007 and followed up until 2009. About 62\% patients had grade 3 to 4 severe neutropenia, which was transient and without episode of infection. The median overall survival was 15.0 months and 1-year survival rate was $64.0 \%$.

Recently, there are some trials about fixed-dose-rate gemcitabine, which can maintain a critical plasma concentration of gemcitabine, and thus increase tumor cytotoxicity and therapeutic efficacy (Hochster, 2003). Here are two studies introduced, one reported by Poplin et al. (2009) and the other by Mané et al. (2010). The former study enrolled 275 patients in the gemcitabine group, 277 in the fixed-dose-rate gemcitabine group and 272 in the gemcitabine plus oxaliplatin group. The differences of survival efficacy between these groups did not achieve pre-specified criteria significantly. The fixed-dose-rate gemcitabine group had the worst adverse effects of grade 3 to 4 neutropenia and thrombocytopenia. In the latter study, 62 patients with advanced pancreatic or biliary tree adenocarcinoma were registered, among which 59 were assessable for response. The median time to progression and median overall survival were 21 and 37.71 weeks, respectively. Thus, fixed-dose-rate gemcitabine has an effect on pancreatic cancer and can be considered to be combined with other agents.

Gemcitabine sensitivity can be predicted by hENT1 protein which helps in gemcitabine transport into the cells. Farrell et al. (2009) found that hENT1 protein expression was associated with increased overall survival and disease-free survival in pancreatic cancer patients who received gemcitabine.

\section{S-1}

In Japan, S-1, an oral fluoropyrimidine, which contains tegafur, 5-chloro-2,4-dihydroxypyridine, and potassium oxonate at a molar ratio of 1:0.4:1, based on the biochemical modulation of 5 -fluorouracil, has been identified to have an effect on gemcitabine-refractory pancreatic cancer, as well as chemotherapy naive pancreatic cancer. In a study of metastatic pancreatic cancer with 40 chemo-naïve patients involved, reported from Japanese national cancer hospital (Okusaka et al., 2008), the overall response rate was $37.5 \%$ ( 1 complete response and 14 partial responses). Themedian time to progression and median overall survival were 3.7 and 9.2 months, respectively, as well as mostly tolerable and reversible toxicities. Also, from Japanese national cancer hospital, Morizane et al. (2009) reported a study of 40 
Table 1. Single-agent regimen.

\begin{tabular}{|c|c|c|c|c|c|c|c|c|c|c|}
\hline \multirow{2}{*}{ Study } & \multirow{2}{*}{$\begin{array}{l}\text { Publishing } \\
\text { time }\end{array}$} & \multirow{2}{*}{ Phase } & \multirow{2}{*}{$\begin{array}{c}\text { No. of } \\
\text { patients }\end{array}$} & \multirow{2}{*}{ Treatment } & \multirow{2}{*}{$\begin{array}{c}\text { Median PFS/TTP } \\
\text { (months) }\end{array}$} & \multirow{2}{*}{$\begin{array}{l}\text { Median OS } \\
\text { (months) }\end{array}$} & \multicolumn{3}{|c|}{ Survival rate (\%) } & \multirow{2}{*}{ Comment } \\
\hline & & & & & & & 1 year & 3 years & 5 years & \\
\hline \multirow{2}{*}{ Oettle H } & \multirow{2}{*}{ January 2007} & \multirow{2}{*}{-} & 179 & $\mathrm{G}$ & 13.4 & 22.1 & 72.5 & 34 & 22.5 & \multirow{2}{*}{$\mathrm{RCT}$} \\
\hline & & & 175 & Surgery-only & 6.9 & 20.2 & 72.5 & 20.5 & 11.5 & \\
\hline \multirow{2}{*}{ Ueno $\mathrm{H}$} & \multirow{2}{*}{ September 2009} & \multirow{2}{*}{ III } & 58 & $\mathrm{G}$ & 11.4 & 22.3 & 78 & 48 & 24 & \multirow{2}{*}{ Randomized } \\
\hline & & & 60 & Surgery-only & 5.0 & 18.4 & 75 & 40 & 11 & \\
\hline \multirow[t]{2}{*}{ Ishii H } & \multirow[t]{2}{*}{ January 2010} & \multirow[t]{2}{*}{ II } & 50 & G & - & 15.0 & 64 & - & - & \multirow[t]{2}{*}{-} \\
\hline & & & 275 & $\mathrm{G}$ & 2.6 & 4.9 & 16 & - & - & \\
\hline \multirow[t]{2}{*}{ Poplin E } & \multirow[t]{2}{*}{ August 2009} & \multirow[t]{2}{*}{ III } & 277 & GEM FDR & 3.5 & 6.2 & 21 & - & - & \multirow[t]{2}{*}{ Randomized } \\
\hline & & & 272 & GEMOX & 2.7 & 5.7 & 21 & - & - & \\
\hline Mane JM & May to June 2010 & - & 59 & GEM FDR & $4.9^{\S}$ & 8.8 & - & - & - & Including biliary tree cancer \\
\hline Okusaka T & April 2008 & II & 40 & S-1 & $3.7^{\S}$ & 9.2 & 32.5 & - & - & - \\
\hline Morizane C & January 2009 & II & 40 & S-1 & 2.0 & 4.5 & 14.1 & - & - & - \\
\hline Nakai Y & August 2010 & - & 29 & S-1 & 2.5 & 7.7 & - & - & - & - \\
\hline Sudo K & February 2011 & II & 21 & S-1 & 4.1 & 6.3 & - & - & - & - \\
\hline Ueno $\mathrm{H}$ & March 2007 & II & 40 & 1 & - & 7.3 & 29.5 & - & - & - \\
\hline Yi SY & May 2009 & II & 33 & I & 2.0 & 6.6 & - & - & - & - \\
\hline \multirow{2}{*}{ Ciulean TE } & \multirow{2}{*}{ June 2009} & \multirow{2}{*}{ III } & 148 & Glu+BSC & - & 3.5 & - & - & - & - \\
\hline & & & 155 & BSC & - & 2.8 & - & - & - & Randomized \\
\hline \multirow{2}{*}{ Chabot JA } & \multirow{2}{*}{ April 2010} & - & 23 & Gem-based therapy & - & 14 & 56 & - & - & - \\
\hline & & - & 32 & Proteolytic enzyme & - & 4.3 & 16 & - & - & - \\
\hline Saif MW & February 2010 & II & 56 & GPM & $2.8,3.2^{\S}$ & 6.5 & - & - & - & - \\
\hline
\end{tabular}

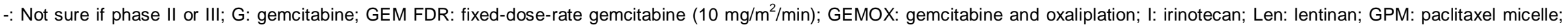

Glu: glufosfamide; BSC: best supportive care. PFS: progression-free survival; TTP (§): time to progression. OS: overall survival; RCT: randomized controlled trial.

of 40 patients with gemcitabine-refractory metastatic pancreatic cancer. Fatigue and anorexia were common, but mostly tolerable and reversible. Partial response rate was $15.95 \%$ without complete response. The median progression-free survival, median overall survival and 1-year survival rate were 2.0 months, 4.5 months and $14.1 \%$, respectively.

Another 2 trials of $\mathrm{S}-1$ in patients with gemcitabine-resistant metastatic pancreatic cancer were published recently by Nakai et al. (2010) and Sudo et al. (2011), respectively. The first study had 108 patients enrolled, among which 29 patients used S-1. The objective response rate, progression-free survival and overall survival for 
Table 2. Combination regimens of two agents.

\begin{tabular}{|c|c|c|c|c|c|c|c|c|c|}
\hline \multirow{2}{*}{ Study } & \multirow{2}{*}{ Publishing time } & \multirow{2}{*}{ Phase } & \multirow{2}{*}{$\begin{array}{l}\text { No. of } \\
\text { patients }\end{array}$} & \multirow{2}{*}{ Treatment } & \multirow{2}{*}{$\begin{array}{c}\text { Median PFS/TTP } \\
\text { (months) }\end{array}$} & \multirow{2}{*}{ Median OS (months) } & \multicolumn{2}{|c|}{ Survival rate (\%) } & \multirow{2}{*}{ Comment } \\
\hline & & & & & & & 1 year & 5 years & \\
\hline Clayton AJ & January 2006 & II & 36 & $\mathrm{G}+\mathrm{Cis}$ & $5.75^{\S}$ & 9.5 & 41.7 & - & - \\
\hline \multirow{2}{*}{ Heinemann V } & \multirow{2}{*}{ August 2006} & \multirow{2}{*}{ III } & 95 & $\mathrm{G}+\mathrm{Cis}$ & 5.3 & 7.5 & 25.3 & - & Randomized \\
\hline & & & 95 & $\mathrm{G}$ & 3.1 & 6.0 & 24.7 & - & \\
\hline \multirow{2}{*}{ Colucci G } & \multirow{2}{*}{ August 2010} & \multirow{2}{*}{ III } & 199 & $\mathrm{G}$ & 3.9 & 8.3 & 34 & - & \multirow[t]{2}{*}{ Randomized } \\
\hline & & & 201 & $\mathrm{G}+\mathrm{Cis}$ & 3.8 & 7.2 & 30.7 & - & \\
\hline Min Kyoung Kim & January 2009 & - & 22 & $\mathrm{G}+\mathrm{S}-1$ & $4.6^{\S}$ & 8.5 & 27.3 & - & Outpatient-based regimen \\
\hline Gyeong-Won Lee & September 2009 & II & 32 & $\mathrm{G}+\mathrm{S}-1$ & $4.92^{\S}$ & 7.89 & - & - & - \\
\hline Oh DY & February 2010 & II & 38 & $\mathrm{G}+\mathrm{S}-1$ & $5.4^{\S}$ & 8.4 & 34 & - & - \\
\hline Lee KH & July 2009 & II & 48 & $\mathrm{G}+\mathrm{OX}$ & $5.6^{\S}$ & 9.4 & - & - & - \\
\hline Fortune BE & 2009 & - & 17 & GEM FDR+OX & 2.6 & 6.4 & 29.4 & - & Following GSDR failure \\
\hline Chiorean TE & 2010 & II & 29 & $\mathrm{G}+\mathrm{Glu}$ & 3.7 & 6 & 32 & - & - \\
\hline Neri B & 2009 & - & 33 & $\mathrm{G}+\mathrm{I}$ & $9.2^{\S}$ & 11.8 & - & - & - \\
\hline \multirow{2}{*}{ Stathopoulos GP } & \multirow{2}{*}{ September 2006} & \multirow{2}{*}{ III } & 71 & $\mathrm{G}+\mathrm{I}$ & $2.8^{\S}$ & 6.4 & 24.3 & - & - \\
\hline & & & 74 & G & $2.9^{\S}$ & 6.5 & 21.8 & - & - \\
\hline \multirow{2}{*}{ Cunningham D } & \multirow{2}{*}{ November 2009} & \multirow{2}{*}{ III } & 266 & $\mathrm{G}$ & 3.8 & 6.2 & 22 & - & \multirow[t]{2}{*}{ Randomized } \\
\hline & & & 267 & $\mathrm{G}+\mathrm{Cap}$ & 5.3 & 7.1 & 24.3 & - & \\
\hline Roehrig S & May 2010 & - & 60 & $\mathrm{G}+5-\mathrm{FU}$ & $4 \S$ & 7.3 & - & - & - \\
\hline Nakamori S & March 2011 & II & 36 & $\mathrm{G}+\mathrm{UFT}$ & - & 7 & - & - & - \\
\hline Melnik MK & August 2010 & II & 40 & $\mathrm{G}+$ Eto & $3.1^{\S}$ & 7.2 & 11.4 & - & - \\
\hline Ridwelski K & April 2006 & II & 43 & $\mathrm{G}+\mathrm{Doc}$ & - & 9.0 & 13.9 & - & - \\
\hline Katopodis O & February 2011 & II & 31 & Cap+Doc & 2.4 & 6.3 & 14.7 & - & - \\
\hline Kim YJ & February 2009 & II & 28 & $5-F U+P a c$ & $2.5^{\S}$ & 7.6 & - & - & - \\
\hline Oh SY & June 2010 & - & 14 & IROX & $1.4^{\S}$ & 4.1 & - & - & Pilot study \\
\hline \multirow{2}{*}{ Kosuge $T$} & \multirow{2}{*}{2006} & \multirow{2}{*}{ - } & 41 & $5-\mathrm{FU}+\mathrm{Cis}$ & - & 12.5 & - & 26.4 & \multirow{2}{*}{$\mathrm{RCT}$} \\
\hline & & & 43 & Nothing & - & 15.8 & - & 14.9 & \\
\hline Mitry E & 2006 & II & 18 & OXFU & 0.9 & 1.3 & - & - & - \\
\hline \multirow{2}{*}{ Neoptolemos JP } & \multirow{2}{*}{2010} & - & 551 & $5-\mathrm{FU}+\mathrm{LV}$ & 23.0 & 14.1 & - & - & - \\
\hline & & - & 537 & $\mathrm{G}$ & 23.6 & 14.3 & - & - & - \\
\hline Epelbaum R & 2010 & - & 17 & $\mathrm{G}+\mathrm{Cur}$ & $2.5 \S$ & 5 & - & - & - \\
\hline
\end{tabular}

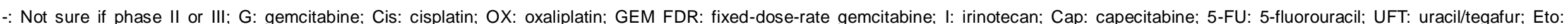

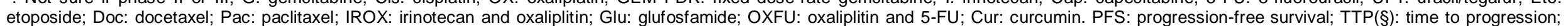
OS: overall survival; RCT: randomized controlled trial; GSDR: standard-dose-rate (30 min) gemcitabine. 
Table 3. Combination regimens of three or more agents.

\begin{tabular}{|c|c|c|c|c|c|c|c|c|}
\hline Study & Publishing time & Phase & $\begin{array}{c}\text { No. of } \\
\text { patients }\end{array}$ & Treatment & $\begin{array}{c}\begin{array}{c}\text { Median PFS/TTP } \\
\text { (months) }\end{array} \\
\end{array}$ & Median OS (months) & 1-year survival rate (\%) & Comment \\
\hline Ghosn M & February 2007 & - & 30 & FOLFOX-6 & $4^{\S}$ & 7.5 & 18.5 & - \\
\hline Novarino A & February 2009 & II & 23 & FOLFOX & $2.7^{\S}$ & 4 & - & - \\
\hline Pelzer U & March 2009 & II & 37 & FOLFOX & $2.8^{\S}$ & 5.13 & - & - \\
\hline Taieb J & March 2007 & II & 40 & FOLFIRI.3 & 5.6 & 12.1 & 51 & - \\
\hline Gebbia V & October 2010 & - & 40 & FOLFIRI & $3.7^{\S}$ & 6 & - & - \\
\hline Conroy $\mathrm{T}$ & May 2011 & - & $\begin{array}{l}171 \\
171\end{array}$ & $\begin{array}{l}\text { FOLFIRIOX } \\
\text { G }\end{array}$ & $\begin{array}{l}6.4 \\
3.3\end{array}$ & $\begin{array}{l}11.1 \\
6.8\end{array}$ & - & Randomized \\
\hline Chang HJ & September 2009 & II & 45 & $\begin{array}{l}\text { GOFL } \\
\text { GEMOXEL }\end{array}$ & $\begin{array}{l}5.1^{\S} \\
4.3\end{array}$ & $\begin{array}{l}8.7 \\
7.8\end{array}$ & - & $\begin{array}{l}- \\
-\end{array}$ \\
\hline Hess V & December 2010 & $\mathrm{I} / \mathrm{II}$ & 45 & - & - & - & - & \\
\hline Pericay Pijaume C & January 2011 & - & 40 & GEMTG & $3.87^{\S}$ & 6.3 & - & - \\
\hline Lee $S$ & 2009 & II & 31 & FAM & $2.3^{\S}$ & 6.7 & - & Incl. other cancers \\
\hline Kruth J & December 2010 & - & 28 & DocMitoCape & 4.5 & 6.8 & - & Incl. other cancers \\
\hline
\end{tabular}

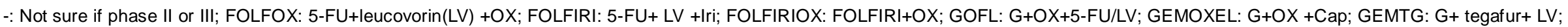
FAM: 5-FU+doxorubicin+mitomycin-C; DocMitoCape: Cap+doxorubicin+mitomycin-C. PFS: Progression-free survival; TTP (§): time to progression.

OS: overall survival.

Table 4. Neoadjuvant/preoperative chemotherapy.

\begin{tabular}{|c|c|c|c|c|c|c|c|c|c|c|}
\hline \multirow{2}{*}{ Study } & \multirow{2}{*}{$\begin{array}{l}\text { Publishing } \\
\text { time }\end{array}$} & \multirow{2}{*}{ Phase } & \multirow{2}{*}{$\begin{array}{c}\text { No. of } \\
\text { patients }\end{array}$} & \multirow{2}{*}{ Treatment } & \multirow{2}{*}{ 1-year survival rate (\%) } & \multirow{2}{*}{ Resection rate (\%) } & \multirow{2}{*}{ Median OS (months) } & \multicolumn{2}{|c|}{ Surgical radicality (\%) } & \multirow{2}{*}{ Comments } \\
\hline & & & & & & & & Ro & NO & \\
\hline \multirow{2}{*}{ Palmer DH } & \multirow{2}{*}{ July 2007} & \multirow{2}{*}{ II } & 24 & $\mathrm{G}$ & 42 & 38 & 9.9 & 75 & 25 & \multirow{2}{*}{ Randomized } \\
\hline & & & 26 & $\mathrm{G}+\mathrm{Cis}$ & 62 & 70 & 15.6 & 75 & 44 & \\
\hline Heinrich S & May 2008 & II & 28 & $\mathrm{G}+\mathrm{Cis}$ & - & 93 & 26.5 & 80 & - & - \\
\hline Sahora K & March 2011 & II & 33 & $\mathrm{G}+\mathrm{OX}$ & - & 39 & $22_{(1)}, 12_{(2)}$ & 69 & - & - \\
\hline
\end{tabular}

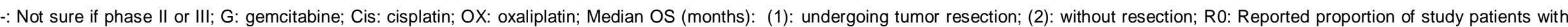
negative resection margins; N0: negative lymph nodes. 
Table 5. Targeted therapy.

\begin{tabular}{|c|c|c|c|c|c|c|c|c|c|c|}
\hline \multirow{2}{*}{ Study } & \multirow{2}{*}{ Publishing time } & \multirow{2}{*}{ Phase } & \multirow{2}{*}{$\begin{array}{c}\text { No. of } \\
\text { patients }\end{array}$} & \multirow{2}{*}{ Treatment } & \multirow{2}{*}{$\begin{array}{c}\text { Median PFS/TTP } \\
\text { (months) }\end{array}$} & \multirow{2}{*}{$\begin{array}{c}\text { Median OS } \\
\text { (months) }\end{array}$} & \multicolumn{3}{|c|}{ Survival rate (\%) } & \multirow{2}{*}{ Comments } \\
\hline & & & & & & & 1 year & 2 years & 3 years & \\
\hline Feliu J & January 2011 & II & 42 & GEM FDR+Erl & $5^{\S}$ & 8 & 35 & - & - & - \\
\hline Okusaka T & February 2011 & II & 107 & $\mathrm{G}+\mathrm{Erl}$ & 3.48 & 9.23 & 33 & - & - & - \\
\hline \multirow{2}{*}{ Raymond E } & \multirow{2}{*}{ February 2011} & \multirow{2}{*}{ III } & 86 & Sun & 11.4 & - & - & - & - & \multirow{2}{*}{$\mathrm{RCT}$} \\
\hline & & & 85 & $\mathrm{PI}$ & 5.5 & - & - & - & - & \\
\hline Fountzilas G & November 2008 & II & 53 & Gef & 4.1 & 7.3 & 27 & - & - & - \\
\hline Mitry E & July 2010 & II & 22 & Mas & $6.4^{\S}$ & 7.1 & - & - & - & - \\
\hline Strumberg D & December 2010 & II & 56 & $\mathrm{Nim}$ & 1.56 & 4.2 & - & - & - & - \\
\hline Kullmann F & April 2009 & II & 64 & $\mathrm{Cet}+\mathrm{G}+\mathrm{OX}$ & $3.9^{\S}$ & 7.1 & - & - & - & - \\
\hline \multirow{2}{*}{ Philip PA } & \multirow{2}{*}{ August 2010} & \multirow{2}{*}{ III } & 357 & $\mathrm{G}$ & 3 & 5.9 & - & - & - & - \\
\hline & & & 362 & $\mathrm{Cet}+\mathrm{G}$ & 3.4 & 6.4 & - & - & - & - \\
\hline \multirow{2}{*}{ Kindler HL } & \multirow{2}{*}{ August 2010} & \multirow{2}{*}{ III } & 302 & $\mathrm{G}+\mathrm{Bev}$ & 3.8 & 5.8 & - & - & - & \multirow{2}{*}{$\mathrm{RCT}$} \\
\hline & & & 300 & $\mathrm{G}+\mathrm{PI}$ & 2.9 & 5.9 & - & - & - & \\
\hline Javle M & June 2009 & II & 50 & $\mathrm{G}+\mathrm{Cap}+\mathrm{Bev}$ & 5.8 & 9.8 & 35.5 & - & - & - \\
\hline \multirow{2}{*}{ Van Cutsem E } & \multirow{2}{*}{ May 2009} & \multirow{2}{*}{ III } & 301 & $\mathrm{G}+\mathrm{Erl}+\mathrm{Pl}$ & 3.6 & 6.0 & - & - & - & \multirow{2}{*}{ Randomized } \\
\hline & & & 306 & $\mathrm{G}+\mathrm{Erl}+\mathrm{Bev}$ & 4.6 & 7.1 & - & - & - & \\
\hline $\mathrm{Ko} A \mathrm{H}$ & November 2010 & II & 36 & $\mathrm{Erl}+\mathrm{Bev}$ & $1.3^{\S}$ & 3.4 & - & - & - & - \\
\hline \multirow{2}{*}{ Yao JC } & \multirow{2}{*}{ February 2011} & \multirow{2}{*}{-} & 207 & Eve & 11.0 & - & - & - & - & \multirow{2}{*}{ Randomized } \\
\hline & & & 203 & $\mathrm{Pl}$ & 4.8 & - & - & - & - & \\
\hline Lipton A & April 2010 & II & 21 & $\mathrm{G}+\mathrm{Erl}+\mathrm{Cel}$ & & 18 & 80 & 20 & - & - \\
\hline \multirow{2}{*}{ Saif MW } & \multirow{2}{*}{ January- August 2009} & \multirow{2}{*}{ II } & 68 & $\mathrm{LY}+\mathrm{G}$ & 3.7 & 7.1 & - & - & - & Randomized, \\
\hline & & & 67 & $\mathrm{Pl}+\mathrm{G}$ & 3.4 & 8.3 & - & - & - & double-blind \\
\hline Shimizu K & January- February 2009 & - & 29 & Len & - & 12.1 & - & - & 20 & - \\
\hline Yanagimoto $\mathrm{H}$ & September 2010 & II & 21 & PPV & - & 9 & 38 & - & - & - \\
\hline Ramanathan RK & March 2011 & II & 16 & $\mathrm{PX}-12$ & 0.9 & 3.2 & - & - & - & - \\
\hline
\end{tabular}

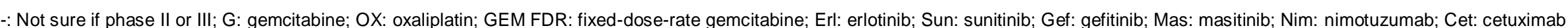

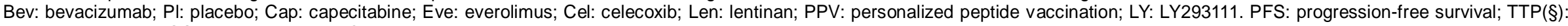
time to progression; OS: overall survival; RCT: randomized control trial. 
second-line chemotherapy with S-1 were $17.2 \%, 2.5$ and 7.7 months, respectively. The second study, with 21 patients enrolled, showed a marked drop of CA19-9 in $28 \%$ of the 18 evaluable patients. The median progression-free survival was 4.1 months and the median overall survival was 6.3 months.

\section{Irinotecan}

Irinotecan, acting by inhibiting DNA topoisomerase, thereby interfering with DNA replication and cell division (Creemers et al., 1994), is active in the treatment of pancreatic cancer. In the National Cancer Center Hospital of Japan (Ueno et al., 2007), 40 patients with metastatic pancreatic cancer were chosen to accept irinotecan and 10 patients obtained responses (overall response rate: $27.0 \%$, partial response rate: $2.7 \%$ ) in 37 assessable patients. The median overall survival was 7.3 months with 29.5\% 1-year survival. Adverse effects were tolerated except that one patient died of disseminated intravascular coagulation syndrome induced by neutropenia with watery diarrhea. In 2009, the Samsung Medical Center of Sungkyunkwan University reported a study of irinotecan as second-line regimen for advanced pancreatic cancer (Yi et al., 2009). Patients (33) pretreated with gemcitabine were included with median age of 59 years. The trial resulted in 2.0 months of median progressionfree survival and 6.6 months of median overall survival, as well as mainly gastrointestinal toxic effects, which were predictable and manageable.

\section{Other drugs}

Recently, researchers have explored some other drugs as monotherapy. Most failed to be identified effective, like glufosfamide (Ciuleanu et al., 2009) and pancreatic proteolytic enzyme (Chabot et al., 2010), probably because of the knowledge limitation. Paclitaxel, a compound abstracted from taxus, can stagnate cell mitosis by promoting the formation of microtubules. Saif et al. (2010) conducted a clinical trial of paclitaxel loaded polymeric micelle (a new formulation of paclitaxel, which has less side effects compared with the traditional one Taxol), which enrolled 56 patients suffering from advanced pancreatic cancer with 3 patients showing response effects (1 complete response, 2 partial responses). The median time to progression was 3.2 months (95\% confidence interval, 2.6 to 4.2), median progression-free survival was 2.8 months (95\% con-fidence interval, 1.4 to 4.0$)$ and median overall survival was 6.5 months (95\% confidence interval, 5.1 to 7.9 ). Disease control rate (complete response + partial response + stable disease) was $60.0 \%$. The study group drew the conclusion that "paclitaxel loaded polymeric micelle monotherapy resulted in overall survival and other efficacy parameters preferable to that seen historically with gemcitabine."

\section{Binary combination}

\section{Gemcitabine and cisplatin}

According to the preclinical evidence that gemcitabine can increase cisplatin-induced DNA cross links and inhibit their repair, and cisplatin can enhance the incorporation of gemcitabine triphosphate into DNA (Peters et al., 1995), the combined use of gemcitabine and cisplatin is reasonable.

Clayton et al. (2006) reported a phase II study to access the combination of gemcitabine and cisplatin in patients with advanced pancreatic cancer. Of the 35 evaluable patients, hematological toxicity was significant, but mostly asymptomatic, with 3 episodes of neutropenic sepsis and 2 severe episodes of bleeding. The median time to progression was 5.75 months, median survival was 9.5 months, 6 -month survival was $72.2 \%$, and 1 -year survival was $41.7 \%$. All of these data were considered effective.

Also in 2006, a randomized phase III trial was reported by Heinemann et al. (2006). 190 patients with advanced pancreatic cancer were randomly assigned to receive gemcitabine and cisplatin or only gemcitabine. The combination treatment group had prolonged median progression-free survival (5.3 vs. 3.1 months) and median overall survival ( 7.5 vs. 6.0 months), which did not achieve statistical differences and higher rate of stable disease ( 60.2 vs. $40.2 \%$; $P<0.001)$.

The latest study from Italy (Colluci et al., 2010) randomly assigned 400 patients to receive gemcitabine alone $(n=199)$ or gemcitabine and cisplatin $(n=201)$. The median overall survival was 8.3 months, median progression-free survival was 3.9 months, objective response rate was $10.1 \%$, and clinical benefit rate was $23.0 \%$ in the gemcitabine group versus 7.2 months, 3.8 months, $12.9 \%$ and $15.1 \%$ in the gemcitabine and cisplatin group. All of these parameters failed to reach statistical significance. Combination therapy was associated with more hematologic toxicities, but without relevant difference in non-hematologic toxicity. Apart from the former two studies, this trial came into a negative result without any improvement compared with gemcitabine alone.

\section{Gemcitabine and S-1}

Three clinical trials from Korea were found in PubMed studying the combination of gemcitabine and $S-1$, all gaining positive findings, thus indicating the utility of the coadunation. The first one, reported by Min Kyoung et al. (2009), who enrolled 22 patients with advanced or metastatic pancreatic cancer, among which 19 patients had metastases, including 11 multiple liver metastases. After 25.4 months of follow-up, the median time to progression and median overall survival were 4.6 (95\% confidence interval, 2 to 7.2 months) and 8.5 months (95\% confidence 
interval, 6.8 to 10.1 months), respectively, and 1-year survival rate was $27.3 \%$, no intolerable adverse effect occurred. 20 patients (91\%) received chemotherapy on an outpatient basis. It seems that gemcitabine plus S-1 are useful and tolerable.

In the same year from Gyeongsang National University (Gyeong-Won et al., 2009), 32 chemo-naïve patients, receiving gemcitabine and $\mathrm{S}-1$, showed $44 \%$ partial response, $25 \%$ stable disease and $25 \%$ progression disease. The median time to progression was 4.92 months (95\% confidence interval: 4.16 to 5.67 months), and the median overall survival was 7.89 months $(95 \%$ confidence interval: 5.96 to 9.82 months). Longer survival time was associated with better performance status.

The last study, enrolling 38 patients with unresectable pancreatic cancer, was reported by Oh et al. (2010). Of 34 assessable patients, 11 achieved partial responses (no complete response). The median time to progression and median overall survival were 5.4 and 8.4 months, respectively, without severe toxicity.

\section{Gemcitabine and oxaliplatin}

It has been indicated in one particular study that the combination of oxaliplatin and gemcitabine in pancreatic tumor-bearing mice has a synergistic antitumor effect (Moschidis et al., 2007). Lee et al. (2009) reported results for a group of 48 patients with advanced pancreatic cancer, who received oxaliplatin and gemcitabine infusion. Of the 44 evaluable patients, the response rate, median overall survival, and median time to progression were $18.2 \%, 9.4$ and 5.6 months, respectively. 16 patients obtained clinical benefits, and the global quality of life scores improved by 11.71 .

Fortune et al. (2009) from the Ohio State University Medical Center reported a study, which focused on the fixed-dose-rate gemcitabine combined with oxaliplatin in 17 patients with metastatic pancreatic cancer refractory to standard-dose-rate gemcitabine. Of all patients, $24 \%$ had partial responses, $29 \%$ had stable disease and $47 \%$ had progressive disease. The median progression-free survival was 2.6 months and the median overall survival was 6.4 months. There was no unexpected toxicity. Interesting activity was shown in this trial, supporting this kind of combination.

\section{Gemcitabine and glufosfamide}

A phase III trial administered gemcitabine and glufosfamide (a cytotoxic alkylating agent prodrug) to patients with metastatic pancreatic cancer previously treated with gemcitabine, showing a slightly increased overall survival compared with best supportive care, but not reaching statistically significance (median survival: 3.4 versus 2.8 months; $P=0.19$ ) (Ciuleanu et al., 2009). Another phase II trial was carried out by Chiorean et al.
(2010) and it showed a promising activity of this combination (confirmed partial response rate: 18\%; stable disease: $39 \%$; progression-free survival: 3.7 months; overall survival: 6 months), but with pronounced hematologic and renal toxicities, needing further researches in the dosage of glufosfamide.

\section{Gemcitabine and fluorouracil/prodrug of fluorouracil}

As an oral and tumor-selective fluoropyrimidine, capecitabine can provide prolonged fluorouracil exposure at lower peak concentrations (Ishikawa et al., 1998) Gemcitabine and capecitabine are both nucleoside analogs by inhibiting different targets and have shown synergistic antitumor activity in an intergroup multicenter phase II study (Stathopoulos et al., 2010). A study (Cunningham et al., 2009) also supported this kind of combination. A total of 533 patients with advanced pancreatic cancer were randomly assigned to gemcitabine (n $=266)$ and gemcitabine plus capecitabine $(n=267)$ arms, resulting in apparent improved objective response rate $(19.1 \%$ vs. $12.4 \% ; P=0.034)$, progression-free survival (hazard ratio, $0.78 ; 95 \%$ confidence interval, 0.66 to $0.93 ; P=0.004$ ) and overall survival (hazard ratio, $0.86 ; 95 \%$ confidence interval, 0.72 to $1.02 ; P=0.08$ ) in the combination group. However, an earlier study from a Swiss group (Bernhard et al., 2008) showed no difference between gemcitabine plus capecitabine $(n=160)$ and gemcitabine $(n=159)$ arms when comparing clinical benefit response (19 versus $20 \%$ ).

Roehrig et al. (2010) reported a study applying palliative first-line treatment of weekly high-dose 5-fluorouracil as $24 \mathrm{~h}$-infusion and gemcitabine to 60 patients with metastatic pancreatic cancer. $7 \%$ patients achieved responses and 59\% achieved tumor control (complete response + partial response + stable disease). Median time to progression and overall survival were 4 months and 7.3 months, respectively. This study also identified the normal range of performance status and tumor markers (CEA and CA19-9) were related with good benefit from the combination therapy.

In a latest trial conducted by Nakamori et al. (2011), pre-administered uracil/tegafur (prodrug of 5-fluorouracil) plus gemcitabine were used in 36 patients with unresectable/recurrent pancreatic cancer, getting the results of $25 \%$ partial response, $56 \%$ stable disease, $19 \%$ progression and 7 months of median overall survival.

\section{Gemcitabine/fluorouracil and alkaloids}

Gemcitabine and irinotecan: Due to the efficacy of gemcitabine or irinotecan as monotherapy, it appears that combining these two agents have encouraging effects. Before 2006, some trials had explored the combination and several achieved positive results. Similar results were reported by Neri et al. (2009) with 33 patients enrolled. Of 
32 evaluable patients, 10 responded to treatment (2 complete responses and 8 partial responses) and 11 got stable diseases. The median time to progression and median survival were 9.2 (95\% confidence interval: 6.0 to 12.4) and 11.8 (95\% confidence interval: 7.7 to 15.9$)$ months, respectively, with $22 \% 2$-year survival.

However, a study of gemcitabine and irinotecan did not achieve statistical increase when compared with gemcitabine monotherapy as first-line treatment in 145 patients (71 in the combination group, 74 in the gemcitabine group) with locally advanced or metastatic pancreatic cancer (Stathopoulos et al., 2006). The overall response rate was: $15 \%$ in the combination group $(95 \%$ confidence interval 5.96 to 24.0 ) and $10 \%$ in the gemcitabine group (95\% confidence interval 2.97 to 17.03). The median time to progression was 2.8 and 2.9 months, median survival time was 6.4 and 6.5 months, and 1 -year survival was 24.3 and $21.8 \%$ for the 2 groups, respectively.

Gemcitabine and etoposide: Activated RAS mutations, which can increase the sensitivity of tumor cell for gemcitabine and etoposide, are present in over $90 \%$ of pancreatic cancer (Barbacid, 1990). According to this theory, a trial to evaluate gemcitabine and etoposide, which comprised of 40 chemo-naïve patients with locally advanced or metastatic pancreatic cancer, was conducted by Melnik et al. (2010). Of 35 evaluable patients, 10 exhibited partial responses, 12 had stable disease and 20 showed a more than 20\% decrease in CA 19-9 biomarker levels. Median overall survival was 7.2 months, median time to progression was 3.1 months and 1-year survival rate was $11.4 \%$. 12 patients showed improved quality of life and 3 patients showed stable situation. The primary dose-limiting toxicities were hematologic toxicity and fatigue.

Gemcitabine and docetaxel: Patients $(n=68)$ with advanced/unresectable/metastasized pancreatic cancer were enrolled in a multicenter phase I $(n=25)$ and phase II study $(n=43)$ and received gemcitabine and docetaxel (Ridwelski et al., 2006). After determining the tolerability maximum of the combined agents in phase I, a total of 139 chemotherapy cycles were conducted in phase II, coming into the results of $18.6 \%$ overall response, $41.9 \%$ stable disease, 9 months of median overall survival and $13.9 \% 1$-year survival rate. In addition, quality of life was acceptable and side effects were moderate. Due to the promising outcomes, further evaluation in a prospective phase III study setting was wanted by the author group.

Capecitabine and docetaxel: A report from Hellenic Oncology Research Group (Katopodis et al., 2011) drew the conclusion that the combination of docetaxel and capecitabine as second-line chemotherapy may confer good disease control associated with improvement of quality of life, due to the results of a trial in 31 patients with metastatic pancreatic cancer. Partial responses were observed in 3 patients, stable disease in 7 and disease progression in 21. The median progression-free survival was 2.4 months and median overall survival was 6.3 months, with the estimated 1 -year survival rate of $14.7 \%$.

5-Fluorouracil and paclitaxel: Another argument to support the combination of fluorouracil and alkaloids as second-line chemotherapy for gemcitabine-refractory pancreatic cancer was offered by Kim et al. (2009). In this trial, of 20 evaluable patients (total 28, receiving paclitaxel and 5 -fluorouracil), 10\% got partial responses and $20 \%$ showed stable disease, with 2.5 and 7.6 months of median time to progression and overall survival, respectively. Besides the earlier combinations, gemcitabine and exatecan were explored by Abou-Alfa et al. (2006), but showed no superior to gemcitabine alone with respect to overall survival.

\section{Fluorouracil and cisplatin/oxaliplatin/leucovorin}

A randomized controlled trial evaluating the effect of 5fluorouracil and cisplatin after curative resection of pancreatic cancer was reported by Kosuge et al. (2006). Patients (89) after surgery were randomized to receive chemotherapy (45 patients, arm A) or nothing (44 patients, arm B) with 4 ineligible patients ( 3 in arm A and 1 in arm B). Toxicity was minor and acceptable among the eligible patients in arm $A$. The estimated 5-year survival rate was $26.4 \%$ in arm A and $14.9 \%$ in arm B. The median duration of survival was 12.5 and 15.8 months, and the recurrence rate at 5 years was 73.6 and $80.8 \%$ in arm $A$ and arm $B$, respectively. The regimen was still safe and tolerable even without statistically significant difference between the results.

In the same year, Mitry et al. (2006) reported the valuable use of oxaliplatin combined with 5 -fluorouracil as second-line treatment of advanced pancreatic cancer which was offered after failure of oxaliplatin alone or infusional 5-fluorouracil alone. 18 out of 32 patients treated in the single-agent arms received oxaliplatin and 5-fluorouracil after progression, showing no objective response and $17 \%$ disease stabilization. Median time to progression from the start of second-line treatment was 0.9 months. Median overall survival was 4.9 months from the start of front-line therapy and 1.3 months from the start of second-line therapy.

Later in 2010, fluorouracil plus leucovorin were identified having identical efficacy with gemcitabine (Median survival: 23.0 vs. 23.6 months; median progression-free survival: 14.1 vs. 14.3 months), but more adverse events in 1088 patients (551 receiving fluorouracil plus leucovorin, 537 receiving gemcitabine) with completely resected pancreatic cancer in a randomized controlled 
trial reported by Neoptolemos et al. (2010).

\section{Irinotecan and oxaliplatin}

For patients with gemcitabine- and 5-fluorouracilrefractory pancreatic cancer, few drugs have been used with relatively good results. In 2010, a pilot study from Korea using irinotecan and oxaliplatin got a partial response rate of $21.4 \%$, a stable disease rate of $28.6 \%$, time to tumor progression of 1.4 months and overall survival of 4.1 months in 14 patients, supporting the regimen as a feasible and tolerable salvage therapy (Oh et al., 2010).

\section{Gemcitabine and curcumin}

Epelbaum et al. (2010) from Rambam Health Care Campus in Israel recruited 17 patients with advanced pancreatic cancer and treated them with curcumin plus gemcitabine. At the beginning of the trial, curcumin was given by mouth and then intolerable side events occurred, causing low compliance and having to reduce the dose. One of the 11 evaluable patients $(9 \%)$ had partial responses, $4(36 \%)$ had stable disease, and $6(55 \%)$ had tumor progression. Time to progression was 1 to 12 months (median 2.5), and overall survival was 1 to 24 months (median 5). The prevention of high oral dose may limit systemic effect of curcumin, which needs to be modified in future study.

\section{Triple or more combination}

\section{FOLFOX}

FOLFOX is short for the combination of 5-fluorouracil, leucovorin and oxaliplatin, having achieved positive evaluations either as second-line or first-line therapy in recent several studies. For example, in 2007, Hotel-Dieu de France University Hospital reported that an interesting response rate and a tolerable level of toxicity were obtained when using FOLFOX-6 as the first-line treatment for locally advanced or metastatic pancreatic cancer (Ghosn et al., 2007)

Two years later, Novarino et al. (2009) analyzing the median time to progression (11.6 weeks) and overall survival (17.1 weeks) of 17 assessable patients (total 23) receiving FOLFOX after been pre-treated with gemcitabine-containing schedule, drew the conclusion that the regimen had some activities and needed further investtigations. A similar trial (Pelzer et al., 2009) of 37 gemcitabine-refractory patients was also treated with FOLFOX, but at a different dosage and dosing interval, drew the same conclusion based on the results: 12 weeks of median time to progression, 22 weeks of median overall survival and $49 \%$ overall disease control (complete remission $=3 \%$; partial remission $=3 \%$; stable disease $>12$ weeks $=43 \%$ ).

\section{FOLFIRI}

FOLFIRI (5-fluorouracil, leucovorin and irinotecan) was recently identified useful as second-line treatment after failure of gemcitabine-based therapy for advanced pancreatic cancer. Taieb et al. (2007) explored this new combination in 40 patients and identified its activity with a manageable toxicity profile, $37.5 \%$ response rate, $27.5 \%$ stable disease, 5.6 months median progression-free survival and 12.1 months overall survival.

A multicenter experience of the Gruppo Oncologico Italia Meridionale (Gebbia et al., 2010) also studied the regimen and summarized that it was able to induce an objective response in a relatively small fraction of the gemcitabine-refractory pancreatic adenocarcinoma patients.

In a latest study reported by Conroy et al. (2011), the trial of FOLFIRINOX (FOLFIRI plus oxaliplatin) as firstline therapy displayed a survival advantage, but an increased toxicity was discovered when compared with gemcitabine. 342 patients with metastatic pancreatic cancer were randomly assigned to receive FOLFIRINOX or gemcitabine. In the comparison of the overall survival median (11.1 versus 6.8 months), median progressionfree survival (6.4 vs. 3.3 months) and objective response rate (31.6 versus $9.4 \%)$, superiority of FOLFIRINOX was obvious $(P<0.001)$. After 6 months of follow-up, $31 \%$ patients in the FOLFIRINOX group had a definitive drop of the quality of life versus $66 \%$ in the gemcitabine group (hazard ratio, $0.47 ; 95 \%$ confidence interval, 0.30 to 0.70 ; $P<0.001)$.

\section{Gemcitabine related combination}

In a study from Taiwan (Ch'ang et al., 2009), using biweekly gemcitabine followed by oxaliplatin and simplified 48-h infusion of 5-fluorouracil/leucovorin (GOFL) in 45 patients with advanced pancreatic cancer, exhibited promising activity on the basis of some datum like overall response rate (33.3\%), disease-control rate $(68.9 \%)$, clinical benefit response rate $(46.2 \%)$, median time to progression (5.1 months) and overall survival (8.7 months).

In 2010, the combination of gemcitabine, oxaliplatin and capecitabine (GEMOXEL) was administered to 45 advanced pancreatic cancer patients, finally manifesting its feasibility (Hess et al., 2010). After a median follow-up of 27.2 months, the median progression-free survival was 4.3 months. Patients lived for a median time of 7.8 months.

In 2011, gemcitabine, oral tegafur and leucovorin (GEMTG) gained promising efficacy and security in a trial (Pericay Pijaume et al., 2011) which recruited 40 advanced pancreatic cancer patients. Overall response rate was $22.5 \%$, median time to progression was 3.87 months, 
median time to treatment failure was 2.97 months and median overall survival was 6.3 months.

\section{Doxorubicin, mitomycin and 5- fluorouracil/capecitabine}

In a study published in 2009, a modified FAM regimen (5fluorouracil, doxorubicin, and mitomycin-C) was used as salvage chemotherapy for pancreatic and biliary tract cancer and was acknowledged as an effective chemotherapy regimen with tolerable toxicity (Lee et al., 2009). Of the 31 patients progressive after gemcitabine-based treatment (15 had pancreatic cancer), 4 patients showed partial responses and 8 had stable disease. The median time to progression and overall survival time were 2.3 and 6.7 months.

Treatment that consisted of capecitabine, doxorubicin, and mitomycin-C was applied to 28 pretreated patients suffering from pancreatic, gallbladder and bile duct cancer in a trial conducted by Kruth et al. (2010) and resulted in a high tumor control rate (6 patients achieving partial remissions, 7 achieving minor remissions, 6 having stable disease), 4.5 months median progressionfree survival, 6.8 months median overall survival and a safety profile.

Apart from the aforementioned classifications, combination of 5-fluorouracil, folinic acid plus cisplatin followed by gemcitabine or the reverse sequence and therapy of gemcitabine administered at a fixed dose rate or in combination with cisplatin, docetaxel, or irinotecan in metastatic pancreatic cancer were explored in a randomized phase III trial (Dahan et al., 2010) and a randomized phase II study (Kulke et al., 2009) res-pectively, but did not get significant difference between these groups.

\section{Neoadjuvant/preoperative chemotherapy}

\section{Gemcitabine and cisplatin}

Palmer et al. (2007) from University of Birmingham reported the results for a group of 50 patients, among which 24 received gemcitabine and 26 received gemcitabine and cisplatin before pancreatic resection. At the end, 27 patients underwent pancreatic resection, 9 in the gemcitabine arm and 18 in the combination arm, without increase in surgical complications. 1-year survival rate was $62 \%$ in the combination group versus $42 \%$ in the gemcitabine group. The advantages of high resection rate and encouraging survival rate were observed in the combination therapy with gemcitabine and cisplatin.

In a study from Swiss Hepato-Pancreato-Biliary Center, the same combination therapy was administered to 28 patients with resectable adenocarcinoma of the pancreatic head (Heinrich et al., 2008). Patients (26) had resectable cancer on restaging examinations and the $\mathrm{R} 0$ resection rate was $80 \%$. Median disease-free survival and overall survival were 9.2 and 26.5 months, with improved quality of life.

A prospective phase II trial also from Heinrich (2008) found that pancreaticoduodenectomy after neoadjuvant chemotherapy was safe and associated with low morbidity and mortality rates. In addition, given histologic response and cytopathic effects, the combination of gemcitabine and cisplatin as neoadjuvant chemotherapy was an effective treatment.

\section{Gemcitabine and oxaliplatin}

Sahora et al. (2011) reported a trial of gemcitabine and oxaliplatin as neoadjuvant treatment for locally advanced, non-metastasized pancreatic cancer and got positive results. Of the 33 patients, $39 \%$ had a curative resection with $69 \%$ R0 resection. Median overall survival of patients who underwent tumor resection was 22 months when compared with 12 months for those without resection. The median recurrence-free survival rate after resection was 10 months.

\section{Targeted therapy}

\section{Inhibitor of tyrosine kinase}

Erlotinib: In many tumors, epidermal growth factor receptor (EGFR) is overexpressed, often related to poor prognosis (Ueda et al., 2004). Erlotinib, an EGFR tyrosine-kinase inhibitor, has been demonstrated having antitumor activity in pancreatic cell lines (Durkin et al., 2003). The use of erlotinib in combination with gemcitabine for chemotherapy-naive patients with locally advanced, unresectable or metastatic pancreatic carcinoma had been approved effective in many studies before 2006. Recently, positive results of 2 phase II trials about erlotinib and gemcitabine have been published. One was from Spain (Feliu et al., 2011), using fixed-doserate gemcitabine in combination with erlotinib. Of the 42 advanced pancreatic cancer patients, 1 achieved complete response, 11 achieved partial responses, 11 showed stable disease and 19 showed progression disease. Median time to progression was 5 months, median overall survival was 8 months and 1 year survival rate was 35\%. The other is from Japan (Okusaka et al., 2011), exhibiting similar toxicity and efficacy in Japanese patients with unresectable pancreatic cancer when compared with Western patients.

Gefitinib: Early in 2008, a trial of another EGFR inhibitor, gefitinib, administered with gemcitabine to 53 patients who suffered from inoperable or metastatic pancreatic cancer, showed promising results (Fountzilas et al., 2008). Responses were seen in 6 patients, as well as stable disease in 12 patients. $92 \%$ had main toxicity of 
myelotoxicity. Median progression-free survival was 4.1 months and median survival was 7.3 months with 1 year survival rate of $27 \%$.

Sunitinib: A multinational, randomized, double-blind, placebo-controlled phase III trial of sunitinib, a tyrosine kinase inhibitor of platelet-derived growth factor receptor (PDGFR) and vascular endothelial growth factor receptor (VEGFR) for the treatment of pancreatic neuroendocrine tumors was carried out by Raymond et al. (2011) based on the active results in preclinical models and phase I and II trials. 171 patients were randomly assigned in a $1: 1$ ratio to receive either sunitinib or placebo with best supportive care. The study had to be halted early because of more serious adverse events and deaths in the placebo group and a difference in progression-free survival favoring sunitinib, even though advantages can still be seen in the sunitinib group. Compared with 5.5 months in the placebo group, median progression-free survival of the sunitinib group was 11.4 months (hazard ratio for progression or death, 0.42 ; $95 \%$ confidence interval, 0.26 to $0.66 ; P<0.001$ ). In addition, the objective response rate was apparently higher in the sunitinib group (9.3 versus. $0 \%$ ). At the end of observation, 9 deaths were reported in the sunitinib group $(10 \%)$ versus 21 deaths in the placebo group (25\%) (hazard ratio for death, $0.41 ; 95 \%$ confidence interval, 0.19 to $0.89 ; \mathrm{P}=0.02$ ).

Masitinib: Masitinib is a selective kinase inhibitor that blocks c-kit, PDGFR, Lyn, focal adhesion kinase phosphorrylation activity and to a lesser extent the fibroblast growth factor receptor 3 tyrosine kinase activities, all of these playing important roles in pancreatic cancer progression. A report about the safety and activity of masitinib combined with gemcitabine in 22 patients was published Mitry et al. (2010). The median time to progresssion was 6.4 months and median overall survival was 7.1 months, both longer in patients with locally advanced pancreatic cancer and Karnofsky score (80 to $100)$ than those with metastatic pancreatic cancer or Karnofsky score (70). All these encouraging datum supported the initiation of a phase III trial.

\section{Monoclonal antibodies}

Nimotuzumab/cetuximab: Nimotuzumab, a humanized monoclonal anti-EGFR antibody, was confirmed safe and well tolerated, and showed higher progression-free survival in stable disease patients (complete response: 0; partial response: 0; stable disease: 6 patients; median progression-free survival: 19.2 weeks for patients with stable disease, 6.7 for all; median overall survival: 18.1 weeks) in a phase II trial by Strumberg et al. (2010) who signified that a randomized controlled trial combined with gemcitabine had been initiated to improve efficacy.

Cetuximab is a another monoclonal antibody against the EGFR, but no improved outcome was observed neither in a multicenter phase II study by Kullmann et al. (2009) or in a phase III study by Philip et al. (2010).

Bevacizumab: Bevacizumab is a recombinant humanized monoclonal antibody against vascular endothelial growth factor A (VEGF-A) (Ferrara et al., 2004). Kindler et al. (2005) reported promising results of a phase II trial exploring gemcitabine and bevacizumab in metastatic pancreatic cancer patients. Thus, the Cancer and Leukemia Group B evaluated this regimen in a randomized phase III trial (Kindler et al., 2010), getting 13\% response, 5.8 months median overall survival and 3.8 months median progression-free survival in the gemcitabine/bevacizumab group versus $10 \%, 5.9$ and 2.9 months in the gemcitabine/placebo. These data failed to show improved survival.

Javle et al. (2009) explored the combination of gemcitabine, capecitabine and bevacizumab and got active results (complete response rate: 22\%; progression-free survival: 5.8 months; overall survival: 9.8 months). In the same year, Van Cutsem et al. (2009) attempted the addition of bevacizumab to gemcitabine plus erlotinib, but did not observe apparent increase in overall survival (7.1 versus 6.0 months; hazard ratio, 0.89 ; $95 \%$ confidence interval, 0.74 to $1.07 ; \mathrm{P}=0.2087$ ) even with a much longer progression-free survival (4.6 versus 3.6 months; hazard ratio, 0.73; 95\% confidence interval, 0.61 to $0.86 ; \mathrm{P}=0.0002$ ) compared with placebo. In the next year, the therapy of bevacizumab and erlotinib for gemcitabine-refractory metastatic pancreatic cancer was identified safe but relatively ineffective by a phase II trial (Ko et al., 2010).

Ipilimumab: Ipilimumab, able to block the interaction of B7-1/B7-2 and CTLA-4 (CD152) and thus reducing the apoptosis of activated lymphocytes, was used as single agent for locally advanced or metastatic pancreatic adenocarcinoma in a phase II trial reported by (Royal et al., 2010) with one subject experiencing a delayed response which implied further study.

\section{Inhibitor of the mammalian target of rapamycin}

Although, the precise mechanism is unclear, the mammalian target of rapamycin, a protein kinase as the principal mediator of signals in the PI3K/Akt pathway, played an important role in mitogen stimulation (Rowinsky, 2004). Thus, inhibition of mammalian target of rapamycin may be an efficient anticancer strategy for pancreatic cancer.

Everolimus, an oral inhibitor of mammalian target of 
rapamycin was used in 207 patients and showed significantly prolonged progression-free survival (11.0 versus 4.6 months; hazard ratio, 0.35 ; $95 \%$ confidence interval, 0.27 to $0.45 ; P<0.001$ ) and low rate of severe adverse events when compared with placebo $(n=203)$ for advanced pancreatic neuroendocrine tumors in a report from University of Texas M.D. Anderson Cancer Center (Yao et al., 2011).

Javle et al. (2010) investigated mammalian target of rapamycin inhibiter (temsirolimus) and combined mammalian target of rapamycin and EGFR inhibiters (everolimus plus erlotinib) in two prospective clinical trials (Trial A and Trial B). Only 5 patients were enrolled in trial A (2 died within a month, 1 developed dehydration and another developed asthenia). Of the 16 patients in trial B, 15 showed progressive disease as well as 1 nonevaluable. Pretreatment biopsies revealed a higher pAkt/Akt ratio in tumor specimens than that in nonmalignant pancreatic tissue. The author group considered that "Future strategies should aim for a broader targeting of the PI3K pathway in pancreatic cancer".

\section{Inhibitor of cyclooxygenase-2}

Cyclooxygenase-2, over-expressed in 45 to $75 \%$ of pancreatic cancer is identified as being associated with pancreatic carcinogenesis, chemoresistance, increased invasion and promotion of angiogenesis (Merati et al., 2001). In 2010, Lipton et al. (2010) combined celecoxib (a selective oral cyclooxygenase-2 inhibitor) with gemcitabine and irinotecan to treat 21 patients with advanced pancreatic cancer and got partial response rate of $20 \%$ and stable response of $80 \%$, median overall survival of 18 months, $80 \% 1$ year survival and $20 \% 2$ year survival. Moreover, CA19-9 showed a marked reduction in all evaluable patients, pain was relieved and quality of life got improvement in many patients with tolerable toxicity.

\section{Gastrin antagonist}

Gastrin and cholecystokinin, two kinds of gastrointestinal peptides and having similar affinities for the cholecystokinin2 receptor, can stimulate the growth of several human pancreatic cancer cell lines in culture and pancreatic xenograft rodent models (Clerc et al., 2002). Thus, the cholecystokinin2 receptor has become target for the treatment of pancreatic cancer in some trials, of which the latest one was reported by Meyer et al. (2010) using the oral cholecystokinin2 receptor antagonist Z-360 in combination with gemcitabine in patients with advanced pancreatic cancer. 33 patients were randomly allocated to Z-360 $120 \mathrm{mg}(\mathrm{n}=9), 240 \mathrm{mg}(\mathrm{n}=12)$ or placebo $(n=12)$, and they showed a stable disease of $62.5,25$ and $60 \%$, respectively. More patients showed improvement in pain in Z-360 group. An encouraging trend trend towards reduced pain and improved survival was observed for those receiving $120 \mathrm{mg}$ Z-360.

Another cholecystokinin2/gastrin receptor antagonist, gastrazole, showing efficacy but poor oral bioavailability and needing continuous venous infusion was reported initially for 10 patients (Black, 2009).

\section{Other targeted drugs}

LY293111: LY293111 is a novel oral anticancer agent with leukotriene B4 receptor antagonist and peroxisome proliferator-activated receptor gamma agonist properties. The rationale of a randomized double-blind phase II trial comparing gemcitabine plus LY293111 versus gemcitabine plus placebo in advanced adenocarcinoma of the pancreas (Saif et al., 2009) was derived from promising results used alone or in combination with gemcitabine in pancreatic cancer xenograft models (Meyer et al., 2010). However, the results did not demonstrate any benefit of adding LY293111 to gemcitabine.

Lentinan: Lentinan, a kind of glucan in mushroom, can stimulate immunological function mainly by enhancing the functions of T-Lymphocytes and macrophages (Wasser, 2002). A study of orally administered superfine dispersed lentinan for advanced pancreatic cancer from Tokyo Women's Medical University (Shimizu et al., 2009) showed that the median survival time was 12.1 months and $20 \%$ were alive for 3 years in 25 eligible patients, which could be considered effective.

Personalized peptide vaccination: A phase II study (Yanagimoto et al., 2010) of personalized peptide vaccination, combined with gemcitabine for 21 non-resectable pancreatic cancer patients, found boosted cellular and humoral responses in the post-vaccination peripheral blood mononuclear cells and plasma from 14 of 18 and 13 of 18 patients tested, respectively, and showed correlation between immune boosting and overall survival (9.0 months) with a hazard ratio of 0.2 (95\% confidence interval, 0.06 to 0.73 ; log-rank $P=0.0239$ ).

PX-12: PX-12 is a small molecular irreversible inhibitor of thioredoxin-1, a proto-oncogene that stimulates tumor growth and inhibits apoptosis (Kirkpatrick et al., 1998). Following progression after gemcitabine-based therapy, PX-12 was tried to be administered to 16 patients with advanced pancreatic cancer and identified well tolerated with uncommon grade $\geq 3$ adverse events (Ramanathan et al., 2011). Two patients had stable disease, which was the best response. There was no consistent decrease in thioredoxin-1 or CA 19-9 levels in the duration of the therapy. As none of the initially treated 16 patients had a 
progression-free survival $>4$ months (median progression-free survival: 0.9 months; median survival: 3.2 months), the investigators terminated the study early.

Tipifarnib: K-ras mutations are responsible for permanent activation of the K-ras oncoprotein and are found in 70 to $90 \%$ of pancreatic cancers. Tipifarnib, a farnesyltransferase inhibitor, finally inhibiting K-ras gene function, seems a rational target in pancreatic cancer research. In a trial (688 patients) (Van Cutsem et al., 2004), no statistically significant differences in survival parameters were observed. The median overall survival for the gemcitabine + tipifarnib arm was 193 versus 182 days for the gemcitabine + placebo arm $(P=0.75)$; 6 month and 1-year survival rates were 53 and 27 versus 49 and $24 \%$ for the control arm, respectively; median progression-free survival was 112 versus 109 days for the control arm.

\section{DISCUSSION}

In the part of single-agent regimen, traditional agents like gemcitabine are the main subjects of researches. For resected pancreatic cancer, significantly longer median disease-free survival after curative resection was observed in the gemcitabine group (about twice than that of the surgery-only group), but without statistically different overall survival in a randomized controlled trial and a randomized phase III trial (Oettle et al., 2007; Ueno et al., 2009). For locally advanced pancreatic carcinoma, gemcitabine monotherapy still demonstrated far better survival than historical data for 5-fluorouracil-based chemotherapy (Ishii et al., 2010). Thus, it is full of enough reasons to recommend gemcitabine as standard treatment for either resected or locally advanced pancreatic cancer. Fixed-dose-rate gemcitabine, a new schedule of administration of gemcitabine, based on the theory that a critical plasma concentration of gemcitabine can increase its tumor cytotoxicity and therapeutic efficacy was considered having relevant antitumor activity in a trial conducted by Mane et al. (2010) and exhibited longer median disease-free survival and overall survival than standard gemcitabine in a phase III, randomized study (Poplin et al., 2009). Apparent toxicity occurred in both trials, which will limit the use of fixed-dose-rate gemcitabine.

In four studies using S-1 as second-line agent to treat gemcitabine-resistant advanced pancreatic cancer (mainly metastatic pancreatic cancer) (Okusaka et al., 2008; Morizane et al., 2009; Nakai et al., 2010; Sudo et al., 2011), median time to progression was more than 2 months (2 to 4.1), median overall survival was more than 4.5 months (4.5 to 9.2) and well tolerated toxicity was observed in all trials, implying its antitumor activity and safety. Compared with other second-line drugs, S-1 is more feasible and convenient because it can be given orally. Single-agent irinotecan was explored as first-line therapy for patients with metastatic pancreatic cancer in a trial conducted by national cancer center hospital of Japan (Ueno et al., 2007) and showed noticeable efficacy. Single-agent irinotecan was also explored as second-line treatment in advanced pancreatic cancer $(\mathrm{Yi}$ et al., 2009) and obtained positive outcomes, especially in patients with good performance status. However, these two trials are just phase II studies without matched control groups so that it is hard to conclude that irinotecan can be a good option as first-line or secondline agent for advanced pancreatic cancer. Several trials tried to study new drugs, but few achieved satisfactory data except paclitaxel loaded polymeric micelle. In a trial by Saif et al. (2010), paclitaxel loaded polymeric micelle seemed well tolerated and had comparable efficacy parameters to that seen historically in gemcitabine \pm erlotinib. Currently, preclinical studies of the combination of paclitaxel loaded polymeric micelle with gemcitabine are under performance by the same author group.

Gemcitabine-based combination is the main stream of studies, some getting improved prognosis at some extent. A phase II study (Clayton et al., 2006) supported the efficacy of gemcitabine and cisplatin, but with significant hematological toxicity. A randomized phase III trial (Heinemann et al., 2006) applied modified schedule of the combination and achieved effective and safe results. However, the sample size of the two trials was considered too small to demonstrate the potentially relevant differences in survival. The latest randomized study from Italy (Colucci et al., 2010) consisting of 400 patients, did not show improvement, but decrease even though not reaching statistical significance in the addition of weekly cisplatin to gemcitabine when compared with gemcitabine alone. The use of gemcitabine and cisplatin did not show significant improvement in overall survival (hazard ratio, $0.91 ; 95 \%$ confidence interval, 0.82 to 1.01 ) in the newest meta-analyses updated in this study. There are three clinical trials (Min Kyoung et al., 2009; GyeongWon et al., 2009; Oh et al., 2010) all concluding that gemcitabine and S-1 combination was effective and tolerable with about 8 months median overall survival for locally advanced or metastatic pancreatic cancer in the palliative setting. Randomized controlled trial is needed to demonstrate if it is more efficient than gemcitabine single therapy. Nowadays, the usage of gemcitabine and S-1 in a postoperative adjuvant setting is under investigation.

The authors of a multicenter phase II study (Lee et al., 2009) supported gemcitabine plus oxaliplatin as a reasonable first-line option for advanced pancreatic cancer patients. A small trial (Fortune et al., 2009) explored fixed-dose-rate gemcitabine combined with oxaliplatin and also got encouraging results. In a phase II trial (Chiorean et al., 2010), glufosfamide and gemcitabine exhibited higher response rate (18\% confirmed) and 1year survival $(32 \%)$ than single agent gemcitabine, but 
with more myelosuppressive and nephrotoxic toxicity than that in the glufosfamide alone study (Ciuleanu et al., 2009). The gemcitabine and capecitabine regimen significantly improved response rate and progression-free survival in a phase III randomized trial (Cunningham et al., 2009), but showed no indication of difference in clinical benefit response or quality of life in another phase III randomized trial (Bernhard et al., 2008) when compared with gemcitabine alone. Gemcitabine and 5fluorouracil as a $24 \mathrm{~h}$-infusion were implied as feasible and capable of tumor control with tolerable toxicity in a palliative first-line treatment of metastatic pancreatic cancer (Roehrig et al., 2010). In addition, the oral prodrugs of 5-fluorouracil and uracil/tegafur, also have activity when added to gemcitabine in a multicenter phase II study (Nakamori et al., 2011) having potential value in the outpatient setting.

In a small trial reported by Neri et al. (2009), long median time to progression (9.2 months) and overall survival (11.8 months) were observed in the combination of gemcitabine and irinotecan. However, a multicenter phase III trial (Stathopoulos et al., 2006), which seemed more convincing due to the large sample size and the establishment of control group, did not gain meaningful difference between this combination and gemcitabine alone groups. In a clinical trial (Melnik et al., 2010), the combination of gemcitabine and etoposide was generally well-tolerated and exhibited a response rate $(28 \%)$ similar to other published studies (4.1 to $33 \%$ ). Interestingly, 4 patients showed remarkable overall survival, among which 2 living more than 2 years. The authors offered a hypothesis that specific molecular subsets particularly sensitive to this regimen might exist, needing follow-up researches. In a phase I/II study (Ridwelski et al., 2006), weekly administration of docetaxel at a lower dosage plus gemcitabine showed a higher overall response rate than single infusion of a high dosage of docetaxel protocol used before, implying the importance of dosage and administration intervals. The addition of curcumin to gemcitabine was newly explored just in a small trial (only 17 patients) (Epelbaum et al., 2010) and the formulations of curcumin was not optimal, which needs further studies of large size sample.

Recently, due to the frequency of gemcitabinerefractory, second-line combination has become more important. Combination chemotherapy associated with fluorouracil or its pro-drugs is a nice trend of research. For example, in a study from Hellenic Oncology Research Group (Katopodis et al., 2011), a degree of activity and good tolerance of the combination of docetaxel and capecitabine were indicated in patients with advanced pancreatic adenocarcinoma in a palliative setting. In a study for patients with gemcitabine-resistant pancreatic cancer but good performance status (Kim et al., 2008), 5-fluorouracil and paclitaxel were deemed as a good therapeutic choice. Another study (Mitry et al., 2006) brought arguments, although quite modest to support the value of second-line chemotherapy of 5fluorouracil plus oxaliplatin. Compared with gemcitabine, the combination of fluorouracil and leucovorin was identified having equal efficacy in a randomized controlled trial (Neoptolemos et al., 2010), while in another randomized controlled trial (Kosuge et al., 2006), 5-fluorouracil and cisplatin failed to show any significant benefit.

What can we do if failing after gemcitabine-based and 5-fluorouracil-based treatment? Few studies have focused on this issue. In 2010, a pilot study from Korea (Oh et al., 2010) demonstrated that the irinotecan and oxaliplatin regimen constituted a feasible and tolerable salvage therapy in patients with gemcitabine-refractory and 5-fluorouracil-refractory advanced pancreatic cancer. More exploratory studies like this are wanted.

Different regimens consisting of more than 2 agents have been involved in many trials but mostly without comparison groups so that definitive conclusions are difficult to make. Even though, inspirations still can be seen from these trials. For example, FOLFOX with various schedules of administration was deemed as a safe and active regimen either as first-line treatment (Neoptolemos et al., 2010) or as second-line treatment (Novarino et al., 2009; Pelzer et al., 2009). FOLFIRI, administered in different methods, also showed promising activity in the fighting with pancreatic cancer (Taïeb et al., 2007; Gebbia et al., 2010). Especially in a randomized trial (Conroy et al., 2011), FOLFIRI added with oxaliplatin had a convincing advantage of median progression-free survival and overall survival. Otherwise, a randomized phase II trial comparing FOLFIRI.3 with FOLFOX identified modest activities of the 2 regimens in pre-treated patients, no superior nor inferior to each other (Yoo et al., 2009). Gemcitabine related combinations, like GOFL, GEMOXEL or GEMTG, exhibited similar median overall survival with a range of 6.3 to 8.7 and merited further investigations. Doxorubicin, mitomycin and 5-fluorouracil/ capecitabine were used together as salvage therapy for billio-pancreatic cancer in two trials (Lee et al., 2009; Kruth et al., 2010) and got an average median overall survival of 6.75 months, not bad results in terms of second-line therapy.

Due to the potential benefits like increasing the rate of adjuvant therapy, early treatment of micrometastases, conversion of non-resectable to resectable disease, etc., neoadjuvant therapy has been researched in many trials, among which most are related with chemoradiotherapy. Here, only preoperative chemotherapy is within the range of discussion and merely 4 relative trials ( 3 about gemcitabine and cisplatin (Palmer et al., 2007; Heinrich et al., 2008), 1 about gemcitabine and oxaliplatin (Sahora et al., 2011) were found. Through these trials, the trend of down-staging locally advanced pancreatic cancer from a non-resectable to resectable stage and the safety of the following surgery were observed. However, information bias should be considered because the subjective definition of resectability always varies on the basis of 
different institutions' level.

The development of targeted therapy is flourishing nowadays and breakthrough may be made in this reign in the future. Various growth factor receptors such as epidermal growth factor receptor (EGFR), Vascular endothelial growth factor receptor (VEGFR), Platelet-derived growth factor receptors (PDGFR), etc., have become the most common targeted sites, most of which are tyrosine kinase inhibitors, including erlotinib, gefitinib, sunitinib and masitinib. Consistent with results before, erlotinib, an inhibitor of EGFR, was characterized as safe and effective when combined with gemcitabine in two recent trials (Feliu et al., 2010; Okusaka et al., 2011). So, erlotinib plus gemcitabine is a good option with little risk. Another tyrosine kinase inhibitor of EGFR, gefitinib, has been demonstrated to be having promising activity combined with gemcitabine in a phase II study (Fountzilas et al., 2008) and needs further investigations. The data from a randomized controlled trial (Raymond et al., 2011) showed that using sunitinib rationally to inhibit VEGFR and PDGFR resulted in meaningful improvements in progression-free survival, objective response rate, and overall survival among patients with pancreatic neuroendocrine tumors. Moreover, based on a phase II studies, Mitry (2010) deemed that masitinib, mainly blocking c-kit, PDGFR and focal adhesion kinase, was encouraging in the treatment of advanced pancreatic cancer and deserved a phase III trial.

Nimotuzumab and cetuximab, as monoclonal antibodies against EGFR, show flat activity for treating pancreatic cancer. For example, in a multicenter phase II study (Kullmann et al., 2009), the addition of cetuximab to the combination of gemcitabine and oxaliplatin did not result in a prolonged survival in comparison with earlier studies evaluating gemcitabine plus oxaliplatin only. According to the newest research (Garrido et al., 2009), nimotuzumab binds bivalently to the overexpressed EGFR in tumor cells, and transiently binds monovalently to the receptor in normal cells, while cetuximab binds tightly in neither tumor nor normal cells. Thus, less toxicity will be caused by nimotuzumab.

Since 2006, a total of 4 trials tried bevacizumab (against VEGF-A) in combination with different agents (including 1 randomized controlled trial) for treating various stages of pancreatic cancer and drew different conclusions. It is hard to feature bevacizumab as effective or not because of too many varieties. In a randomized controlled trial (Kindler et al., 2010), no survival benefit was gotten from bevacizumab even when combined with gemcitabine.

Many new sites, including CTLA-4, mammalian target of rapamycin, cyclooxygenase-2, cholecystokinin2 receptor, leukotriene B4 receptor, peroxisome proliferator-activated receptor gamma and protooncogene, have become targets in many trials. Besides, some specific immunopotentiators, like lentinan and personalized peptide vaccination, have been explored in some trials (Wasser et al., 2002; Shimizu et al., 2009).
No matter the results obtained in these trials, whether good or bad, lots of implications can be made, which may become rationales of further explorations.

\section{Conclusion}

Gemcitabine-based chemotherapy is still under investigations and can be considered the first choice for treating pancreatic cancer so far. More prospective randomized trials using a controlled arm without treatment are needed to definitely demonstrate and validate the role of second-line treatment in gemcitabine-refractory pancreatic cancer. Targeting the specific biologic mechanisms involved in pancreatic cancer cell proliferation and metastasis, has been deemed as a new therapeutic approach with nice prospect.

\section{ACKNOWLEDGEMENTS}

This work was supported in part by grants from the National Natural Science Foundation of China (No. 30972910) and China Postdoctoral Science Foundation (No. 20060390294).

\section{REFERENCES}

Abou-Alfa GK, Letourneau R, Harker G, Modiano M, Hurwitz $H$, Tchekmedyian NS, Feit K, Ackerman J, De Jager RL, Eckhardt SG, O'Reilly EM (2006). Randomized phase III study of exatecan and gemcitabine compared with gemcitabine alone in untreated advanced pancreatic cancer. J. Clin. Oncol. 24(27):4441-7.

Arshad A, Al-Leswas D, Al-Taan O, Stephenson J, Metcalfe M, Steward WP, Dennison AR (2011). Pooled Survival and Response Data From Phase III Randomized Controlled Trials for Gemcitabine-based cancer. Clin. Transl. Oncol. 13(1):61-6.

Barbacid M (1990). Ras oncogenes: their role in neoplasia. Eur. J. Clin. Invest. 20:225-35.

Bernhard J, Dietrich D, Scheithauer W, Gerber D, Bodoky G, Ruhstaller T, Glimelius B, Bajetta E, Schüller J, Saletti P, Bauer J, Figer A, Pestalozzi BC, Köhne $\mathrm{CH}$, Mingrone W, Stemmer SM, Tàmas K, Kornek GV, Koeberle D, Herrmann R (2008) . Central European cooperative Oncology Group. Clinical benefit and quality of life in patients with advanced pancreatic cancer receiving gemcitabine plus capecitabine versus gemcitabine alone: a randomized multicenter phase III clinical trial--SAKK 44/00-CECOG/PAN. 1.3.001. J. Clin. Oncol. 26(22):3695-701.

Black JW (2009). Reflections on some pilot trials of gastrin receptor blockade in pancreatic cancer. Eur. J. Cancer 45(3):360-4.

Bramhall SR, Allum WH, Jones AG, Allwood A, Cummins C, Neoptolemos JP (1995). Treatment and survival in 13,560 patients with pancreatic cancer: an epidemiological study in the West Midlands. Br. J. Surg. 82:111-5.

Burris HA, Moore MJ, Andersen J, Green MR, Rothenberg ML, Modiano MR, Cripps MC, Portenoy RK, Storniolo AM, Tarassoff $P$, Nelson R, Dorr FA, Stephens CD, Von Hoff DD (1997). Improvements in survival and clinical benefit with gemcitabine as first-line therapy for patients with advanced pancreas cancer: a randomized trial. J. Clin. Oncol. 15:2403-2413.

Chabot JA, Tsai WY, Fine RL, Chen C, Kumah CK, Antman KA, Grann VR (2010). Pancreatic proteolytic enzyme therapy compared with gemcitabine-based chemotherapy for the treatment of pancreatic cancer. J. Clin. Oncol. 28(12):2058-63.

Ch'ang HJ, Huang CL, Wang HP, Shiah HS, Chang MC, Jan CM, Chen JS, Tien YW, Hwang TL, Lin JT, Cheng AL, Whang-Peng J, Chen LT 
(2009). Phase II study of biweekly gemcitabine followed by oxaliplatin and simplified 48-h infusion of 5-fluorouracil/leucovorin (GOFL) in advanced pancreatic cancer. Cancer Chemother. Pharmacol. 64(6):1173-9.

Chiorean EG, Dragovich T, Hamm J, Barrios CH, Gorini CF, Langmuir VK, Kroll S, Jung DT, Tidmarsh GT, Loehrer PJ (2010). A phase 2 trial of glufosfamide in combination with gemcitabine in chemotherapy-naive pancreatic adenocarcinoma. Am. J. Clin Oncol. 33(2):111-6.

Ciuleanu TE, Pavlovsky AV, Bodoky G ,Garin AM, Langmuir VK, Stewart Kroll, Tidmarsh GT (2009). A randomised Phase III trial of glufosfamide compared with best supportive care in metastatic pancreatic adenocarcinoma previously treated with gemcitabine. Eur. J. Cancer. 45(9):1589-96. Epub 2009 Jan 31.

Clayton AJ, Mansoor AW, Jones ET, Hawkins RE, Saunders MP Swindell R, Valle JW (2006). A phase II study of weekly cisplatin and gemcitabine in patients with advanced pancreatic cancer: is this a strategy still worth pursuing? Pancreas 32(1):51-7.

Clerc P, Leung-Theung-Long S, Wang TC, Dockray GJ, Bouisson M, Delisle MB, Vaysse N, Pradayrol L, Fourmy D, Dufresne M (2002). Expression of CCK2 receptors in the murine pancreas: proliferation, transdifferentiation of acinar cells, and neoplasia. Gastroenterol. 122(2):428-37.

Colucci G, Labianca R, Di Costanzo F, Gebbia V, Cartenì G, Massidda B, Dapretto E, Manzione L, Piazza E, Sannicolò M, Ciaparrone M, Cavanna L, Giuliani F, Maiello E, Testa A, Pederzoli P, Falconi M, Gallo C, Di Maio M, Perrone F (2010). Randomized phase III trial of gemcitabine plus cisplatin compared with single-agent gemcitabine as first-line treatment of patients with advanced pancreatic cancer: The GIP-1 study. J. Clin. Oncol. 28(10):1645-51.

Conroy T, Desseigne F, Ychou M, Bouché O, Guimbaud R, Bécouarn Y, Adenis A, Raoul JL, Gourgou-Bourgade S, de la Fouchardière C, Bennouna J, Bachet JB, Khemissa-Akouz F, Péré-Vergé D, Delbaldo C, Assenat E, Chauffert B, Michel P, Montoto-Grillot C, Ducreux M (2011). FOLFIRINOX versus gemcitabine for metastatic pancreatic cancer. N. Engl. J. Med. 364(19):1817-25.

Creemers GJ, Lund B, Verweij J (1994) Topoisomerase I inhibitors: topotecan and irenotecan. Cancer Treat. Rev. 20:73-96.

Cunningham D, Chau I, Stocken DD, Valle JW, Smith D, Steward W, Harper PG, Dunn J, Tudur-Smith C, West J, Falk S, Crellin A, Adab F, Thompson J, Leonard P, Ostrowski J, Eatock M, Scheithauer W, Herrmann R, Neoptolemos JP (2009). Phase III randomized comparison of gemcitabine versus gemcitabine plus capecitabine in patients with advanced pancreatic cancer. J. Clin. Oncol. 27(33):5513-8.

Dahan L, Bonnetain F, Ychou M, Mitry E, Gasmi M, Raoul JL, Cattan S, Phelip JM, Hammel P, Chauffert B, Michel P, Legoux JL, Rougier P, Bedenne L, Seitz JF (2010). Combination 5-fluorouracil, folinic acid and cisplatin (LV5FU2-CDDP) followed by gemcitabine or the reverse sequence in metastatic pancreatic cancer: Final results of a randomised strategic phase III trial (FFCD 0301). Gut 59(11):152734.

Durkin AJ, Bloomston PM, Rosemurgy AS, Giarelli N, Cojita D, Yeatman TJ, Zervos EE (2003). Defining the role of the epidermal growth factor receptor in pancreatic cancer grown in vitro. Am. J. Surg. 186:431-6.

Epelbaum R, Schaffer M, Vizel B, Badmaev V, Bar-Sela G (2010). Curcumin and gemcitabine in patients with advanced pancreatic cancer. Nutr. Cancer 62(8):1137-41.

Farrell JJ, Elsaleh H, Garcia M, Lai R, Ammar A, Regine WF, Abrams $\mathrm{R}$, Benson $\mathrm{AB}$, Macdonald J, Cass CE, Dicker AP, Mackey JR (2009). Human equilibrative nucleoside transporter 1 levels predict response to gemcitabine in patients with pancreatic cancer. Gastroenterol. 136(1):187-95.

Feliu J, Borrega P, León A, López-Gómez L, López M, Castro J, Belda-Iniesta C, Barriuso J, Martínez V, González-Barón M (2011). Phase II study of a fixed dose-rate infusion of gemcitabine associated with erlotinib in advanced pancreatic cancer. Cancer Chemother. Pharmacol. 67(1):215-21.

Ferrara N, Hillan KJ, Gerber HP, Novotny W (2004). Discovery and development of bevacizumab, an anti-VEGF antibody for treating cancer. Nat. Rev. Drug Discov. 3:391-400
Fortune BE, Li X, Kosuri KV, Weatherby LM, Thomas JP, Bekaii-Saab TS (2009). Fixed-dose-rate gemcitabine in combination with oxaliplatin in patients with metastatic pancreatic cancer refractory to standard-dose-rate gemcitabine: A single-institute study. Oncology 76(5):333-7.

Fountzilas G, Bobos M, Kalogera-Fountzila A, Xiros N, Murray $S$, Linardou H, Karayannopoulou G, Koutras AK, Bafaloukos D, Samantas E, Christodoulou C, Economopoulos T, Kalogeras KT, Kosmidis P (2008). Gemcitabine combined with gefitinib in patients with inoperable or metastatic pancreatic cancer: a phase II Study of the Hellenic Cooperative Oncology Group with biomarker evaluation. Cancer Investig. 26(8):784-93.

Garrido G, Rabasa A, Gracia E, Tikhomirov I, Crombet-Ramos T, Viloria-Petit A, Kerbel RS, Yang E, Perez R (2009). Nimotuzumab, an antitumor antibody that targets the epidermal growth factor receptor, blocks ligand binding while permitting the active receptor conformation. Cancer Res. 69:5851-5859

Gebbia V, Maiello E, Giuliani F, Borsellino N, Arcara C, Colucci G (2010). Irinotecan plus bolus/infusional 5-Fluorouracil and leucovorin in patients with pretreated advanced pancreatic carcinoma: a multicenter experience of the Gruppo Oncologico Italia Meridionale. Am. J. Clin. Oncol. 33(5):461-4.

Ghosn M, Farhat F, Kattan J, Younes F, Moukadem W, Nasr F, Chahine G (2007). FOLFOX-6 combination as the first-line treatment of locally advanced and/or metastatic pancreatic cancer. Am. J. Clin. Oncol. 30(1):15-20.

Gyeong-Won L, Hye JK, Ji-Hyun J, Seok-Hyun K, Hoon GK, Tae HK, Hyun JK, Chi-Young J, Jung HK (2009). Phase II trial of S-1 in combination with gemcitabine for chemo-naïve patients with locally advanced or metastatic pancreatic cancer. Cancer Chemother. Pharmacol. 64(4):707-13.

Heinemann V, Hertel LW, Grindey GB, Plunkett W (1988). Comparison of the cellular pharmacokinetics and toxicity of 2',2'-difluoro-2'deoxycytidine and 1-B-D-arabinofuranosylcytosine. Cancer Res. 48:4024-4031.

Heinemann V, Quietzsch D, Gieseler F, Gonnermann M, Schönekäs H, Rost A, Neuhaus H, Haag C, Clemens M, Heinrich B, Vehling-Kaiser $U$, Fuchs M, Fleckenstein D, Gesierich W, Uthgenannt D, Einsele H, Holstege A, Hinke A, Schalhorn A, Wilkowski R (2006). Randomized phase III trial of gemcitabine plus cisplatin compared with gemcitabine alone in advanced pancreatic cancer. J. Clin. Oncol. 24(24):3946-52.

Heinrich S, Pestalozzi BC, Schäfer M, Weber A, Bauerfeind P, Knuth A Clavien PA (2008). Prospective phase II trial of neoadjuvant chemotherapy with gemcitabine and cisplatin for resectable adenocarcinoma of the pancreatic head. J. Clin. Oncol. 26(15):2526-31.

Heinrich S, Schäfer M, Weber A, Hany TF, Bhure U, Pestalozzi BC, Clavien PA (2008). Neoadjuvant chemotherapy generates a significant tumor response in resectable pancreatic cancer without increasing morbidity: results of a prospective phase II trial. Ann. Surg. 248(6):1014-22.

Hess V, Pratsch S, Potthast S, Lee L, Winterhalder R, Widmer L, Cescato C, Lohri A, Jost L, Stillhart P, Pestalozzi B, Herrmann R (2010). Combining gemcitabine, oxaliplatin and capecitabine (GEMOXEL) for patients with advanced pancreatic carcinoma (advanced pancreatic cancer): A phase I/II trial. Ann. Oncol. 21(12):2390-5.

Hochster HS (2003). Newer approaches to gemcitabine-based therapy of pancreatic cancer: fixed-dose-rate infusion and novel agents. Int. J. Radiat. Oncol. Biol. Phys. 56(4):24-30.

Ishii H, Furuse J, Boku N, Okusaka T, Ikeda M, Ohkawa S, Fukutomi A, Hamamoto Y, Nakamura K, Fukuda H (2010) JCOG Gastrointestinal Oncology Study Group. Phase II study of gemcitabine chemotherapy alone for locally advanced pancreatic carcinoma: JCOG0506. Jpn. J. Clin. Oncol. 40(6):573-9.

Ishikawa T, Utoh M, Sawada N, Nishida M, Fukase Y, Sekiguchi F, Ishitsuka $\mathrm{H}$ (1998). Tumor selective delivery of 5 -fluorouracil by capecitabine, a new oral fluoropyrimidine carbamate, in human cancer xenografts. Biochem. Pharmacol. 55:1091-1097.

Javle M, Yu J, Garrett C, Pande A, Kuvshinoff B, Litwin A, Phelan J 3rd, Gibbs J, lyer R (2009). Bevacizumab combined with gemcitabine and capecitabine for advanced pancreatic cancer: a phase II study. Br. J. 
Cancer. 100(12):1842-5.

Javle MM, Shroff RT, Xiong H, Varadhachary GA, Fogelman D, Reddy SA, Davis D, Zhang Y, Wolff RA, Abbruzzese JL (2010). Inhibition of the mammalian target of rapamycin (mammalian target of rapamycin) in advanced pancreatic cancer: results of two phase II studies. BMC Cancer 10:368.

Katopodis O, Polyzos A, Kentepozidis N, Giassas S, Rovithi M, Bozionelou V, Kalbakis K, Vamvakas L, Mavroudis D, Georgoulias V (2011). Second-line chemotherapy with capecitabine (Xeloda) and docetaxel (Taxotere) in previously treated, unresectable adenocarcinoma of pancreas: The final results of a phase II trial. Cancer Chemother. Pharmacol. 67(2):361-8.

Kelly DM, Benjamin IS (1995). Pancreatic carcinoma. Ann. Oncol. 6:1928.

Kim YJ, Bang S, Park JY, Park SW, Chung JB, Song SY (2009). Phase II study of 5-fluorouracil and paclitaxel in patients with gemcitabinerefractory pancreatic cancer. Cancer Chemother. Pharmacol. 63(3):529-33.

Kindler HL, Friberg G, Singh DA, Locker G, Nattam S, Kozloff M, Taber DA, Karrison T, Dachman A, Stadler WM, Vokes EE (2005). Phase II trial of bevacizumab plus gemcitabine in patients with advanced pancreatic cancer. J. Clin. Oncol. 23:8033-8040.

Kindler HL, Niedzwiecki D, Hollis D, Sutherland S, Schrag D, Hurwitz H, Innocenti F, Mulcahy MF, O'Reilly E, Wozniak TF, Picus J, Bhargava P, Mayer RJ, Schilsky RL, Goldberg RM (2010). Gemcitabine plus bevacizumab compared with gemcitabine plus placebo in patients with advanced pancreatic cancer: phase III trial of the Cancer and Leukemia Group B (Cancer and Leukemia Group B 80303). J. Clin. Oncol. 28(22):3617-22.

Kirkpatrick DL, Kuperus M, Dowdeswell M, Potier N, Donald LJ, Kunkel M, Berggren M, Angulo M, Powis G (1998). Mechanism of inhibition of the thioredoxin growth factor system by antitumor 2-imidazolyl disulWdes. Biochem. Pharmacol. 55:987-994.

Ko AH, Venook AP, Bergsland EK, Kelley RK, Korn WM, Dito E, Schillinger B, Scott J, Hwang J, Tempero MA (2010). A phase II study of bevacizumab plus erlotinib for gemcitabine-refractory metastatic pancreatic cancer. Cancer Chemother. Pharmacol. 66(6):1051-7.

Kosuge T, Kiuchi T, Mukai K, Kakizoe T (2006). Japanese study Group of Adjuvant Therapy for Pancreatic Cancer (JSAP). A multicenter randomized controlled trial to evaluate the effect of adjuvant cisplatin and 5-fluorouracil therapy after curative resection in cases of pancreatic cancer. Jpn. J. Clin. Oncol. 36(3)159-165.

Kruth J, Nissen J, Ernst T, Kripp M, Lukan N, Merx K, Hofmann

WK,Hochhaus A, Hofheinz RD (2010). Efficacy and safety of capecitabine in combination with docetaxel and mitomycin $\mathrm{C}$ in patients with pre-treated pancreatic, gallbladder, and bile duct carcinoma. J. Cancer Res. Clin. Oncol. 136(12):1845-51.

Kulke MH (2003). Recent developments in the pharmacological treatment of Blaszkowsky L. Treatment of advanced and metastatic pancreatic cancer. Front. Biosci. 3:214-25.

Kulke MH, Tempero MA, Niedzwiecki D, Hollis DR, Kindler HL, Cusnir M, Enzinger PC, Gorsch SM, Goldberg RM, Mayer RJ (2009). Randomized phase II study of gemcitabine administered at a fixed dose rate or in combination with cisplatin, docetaxel, or irinotecan in patients with metastatic pancreatic cancer: Cancer and Leukemia Group B 89904. J. Clin. Oncol. 27(33):5506-12.

Kullmann F, Hollerbach S, Dollinger MM, Harder J, Fuchs $M$, Messmann H, Trojan J, Gäbele E, Hinke A, Hollerbach C, Endlicher E (2009). Cetuximab plus gemcitabine/oxaliplatin (GEMOXCET) in first-line metastatic pancreatic cancer: a multicentre phase II study. Br. J. Cancer 100(7):1032-6.

Lee KH, Kim MK, Kim YH, Ryoo BY, Lim HY, Song HS, Kim HK, Lee MA, Im SA, Chang HM, Cho JY, Zang DY, Kim BS, Kim JS (2009). Gemcitabine and oxaliplatin combination as first-line treatment for advanced pancreatic cancer: A multicenter phase II study. Cancer Chemother. Pharmacol. 64(2):317-25.

Lee S, Oh SY, Kim BG, Kwon HC, Kim SH, Rho MH, Kim YH, Rho MS, Jeong JS, Kim HJ (2009). Second-line treatment with a combination of continuous 5-fluorouracil, doxorubicin, and mitomycin-C (contiFAM) in gemcitabine-pretreated pancreatic and biliary tract cancer. Am. J. Clin. Oncol. 32(4):348-52.
Li D, Xie K, Wolff R, Abbruzzese JL (2004). Pancreatic cancer. Lancet 363:1049-57.

Lipton A, Campbell-Baird C, Witters L, Harvey H, Ali S (2010). Phase II trial of gemcitabine, irinotecan, and celecoxib in patients with advanced pancreatic cancer. J. Clin. Gastroenterol. 44(4):286-8.

Lu Xing H (1997). Current state of diagnosis and development of pancreatic cancer in our nation. Zhong Hua Nei Ke Za Zhi 36(7):435.

Mané JM, Sancho A, Muñoz A, Rubio I, Fernández R, Carrera S, Fuente N, Ballesteros D, Casas R, Marrodán I, Mielgo X, LópezVivanco $G$ (2010). Fixed-dose-rate gemcitabine infusion in patients with advanced pancreatic or biliary tree adenocarcinoma. Tumori 96(3):405-10.

Melnik MK, Webb CP, Richardson PJ, Luttenton CR, Campbell AD, Monroe TJ, O'Rourke TJ, Yost KJ, Szczepanek CM, Bassett MR, Truszkowski KJ, Stein P, Van Brocklin MW, Davis AT, Bedolla G, Vande Woude GF, Koo HM (2010). Phase II trial to evaluate gemcitabine and etoposide for locally advanced or metastatic pancreatic cancer. Mol. Cancer Ther. 9(8):2423-9.

Merati K, said Siadaty M, Andea A, Sarkar F, Ben-Josef E, Mohammad R, Philip P, Shields AF, Vaitkevicius V, Grignon DJ, Adsay NV (2001). Expression of inflammatory modulator cyclooxygenase-2 in pancreatic ductal adenocarcinoma and its relationship to pathologic and clinical parameters. Am. J. Clin. Oncol. 24:447-452.

Meyer T, Caplin ME, Palmer DH, Valle JW, Larvin M, Waters JS, Coxon F, Borbath I, Peeters M, Nagano E, Kato H (2010). A phase Ib/lla trial to evaluate the cholecystokinin2 receptor antagonist Z-360 in combination with gemcitabine in patients with advanced pancreatic cancer. Eur. J. Cancer 46(3):526-33.

Min KK, Kyung HL, Byung IJ, Tae NK, Jong RE, Sung HB, Hun MR, Sun AL, Myung SH (2009). S-1 and gemcitabine as an outpatientbased regimen in patients with advanced or metastatic pancreatic cancer. Jpn. J. Clin. Oncol. 39(1):49-53. Epub 2008 Dec 5.

Mitry E, Ducreux M, Ould-Kaci M, Boige V, Seitz JF, Bugat R, Breau JL, Bouché O, Etienne PL, Tigaud JM, Morvan F, Cvitkovic E, Rougier P (2006). Oxaliplatin combined with 5 -fluorouracil in second line treatment of advanced pancreatic adenocarcinoma. Results of a phase II trial. Gastroenterol. Clin. Biol. 30(3):357-63.

Mitry E, Hammel P, Deplanque G, Mornex F, Levy P, Seitz JF, Moussy A, Kinet JP, Hermine O, Rougier P, Raymond E (2010). Safety and activity of masitinib in combination with gemcitabine in patients with advanced pancreatic cancer. Cancer Chemother. Pharmacol. 66(2):395-403.

Morizane C, Okusaka T, Furuse J, Ishii H, Ueno H, Ikeda M, Nakachi K, Najima M, Ogura T, Suzuki E (2009). A phase II study of S-1 in

gemcitabine-refractory metastatic pancreatic cancer. Cancer Chemother. Pharmacol. 63:313-9.

Moschidis A, Papageorgiou A, Atmatzidis K, Tsalis K, Moschidis E, Livanis J, Chrysogelou E, Mourelatos D, Tsavdaridis D, Harlaftis N (2007). Synergistic antitumor activity of oxaliplatin in combination with gemcitabine in pancreatic tumor-bearing mice. Chemotherapy 53:153-159

Muhammad WS (2008). New Developments in the Treatment of Pancreatic Cancer. Highlights from the "44th ASCO Annual Meeting". JOP. J. Pancreas 9(4):391-397.

Nakai $Y$, Isayama H, Sasaki T, Sasahira N, Kogure H, Hirano K, Tsujino T, ljichi H, Tateishi K, Tada M, Omata M, Koike K (2010). Impact of $\mathrm{S}-1$ in patients with gemcitabine-refractory pancreatic cancer in Japan. Jpn. J. Clin. Oncol. 40(8):774-80.

Nakamori S, Endo W, Ozato H, Shibata T, Takeda Y, Tohno K, Hasuike Y, Masutani S, Morimoto T, Doki Y, Mori M, Monden M (2011). Multicenter phase II study of pre-administered uracil/tegafur (uracil/tegafur) plus gemcitabine for unresectable/recurrent pancreatic cancer. Gan To Kagaku Ryoho. 38(5):789-92.

Neoptolemos JP, Stocken DD, Bassi C, Ghaneh P, Cunningham D, Goldstein D, Padbury R, Moore MJ, Gallinger S, Mariette C, Wente MN, Izbicki JR, Friess H, Lerch MM, Dervenis C, Ola'h A,Butturini G, Doi R, Lind PA, Smith D, Valle JW, Palmer DH, Buckels JA, Thompson

J, McKay CJ, Rawcliffe CL, Büchler MW (2010). Adjuvant chemotherapy with fluorouracil plus folinic acid vs gemcitabine following pancreatic cancer resection: A randomized controlled trial. J. Am. Med. Assoc. 304(10):1073-81.

Neri B, Cipriani G, Grifoni R, Molinara E, Pantaleo P, Rangan S, 
Vannini A, Tonelli P, Valeri A, Pantalone D, Taddei A, Bechi P (2009). Gemcitabine plus irinotecan as first-line weekly therapy in locally advanced and/or metastatic pancreatic cancer. Oncol. Res.17(1112):559-64.

Nitecki SS, Sarr MG, Colby TV, van Heerden JA (1995). Long-term survival after resection for ductal adenocarcinoma of the pancreas. Is it really improving? Ann. Surg. 221:59-66.

Novarino A, Satolli MA, Chiappino I, Giacobino A, Bellone G, Rahimi F, Milanesi E, Bertetto O, Ciuffreda L (2009). Oxaliplatin, 5-fluorouracil, and leucovorin as second-line treatment for advanced pancreatic cancer. Am. J. Clin. Oncol. 32(1):44-8.

Oettle H, Post S, Neuhaus P, Gellert K, Langrehr J, Ridwelski K, Schramm H, Fahlke J, Zuelke C, Burkart C, Gutberlet K, Kettner E, Schmalenberg $\mathrm{H}$, Weigang-Koehler $\mathrm{K}$, Bechstein WO, Niedergethmann M, Schmidt-Wolf I, Roll L, Doerken B, Riess H (2007). Adjuvant chemotherapy with gemcitabine vs observation in patients undergoing curative-intent resection of pancreatic cancer: A randomized controlled trial. J. Am. Med. Assoc. 297(3):267-77.

Oh DY, Cha Y, Choi IS, Yoon SY, Choi IK, Kim JH, Oh SC, Kim CD, Kim JS, Bang YJ, Kim YH (2010). A multicenter phase II study of gemcitabine and S-1 combination chemotherapy in patients with unresectable pancreatic cancer. Cancer Chemother. Pharmacol. 65(3):527-36.

Oh SY, Kim HJ, Kim TH, Lee GW, Kim HG, Jeong CY, Kwon HC, Kang $\mathrm{JH}$ (2010). Pilot study of irinotecan/oxalipltin (irinotecan and oxaliplatin) combination chemotherapy for patients with gemcitabineand 5-fluorouracil- refractory pancreatic cancer. Invest. New Drugs 28(3):343-9.

Okusaka T, Funakoshi A, Furuse J, Boku N, Yamao K, Ohkawa S, Saito H (2008). A late phase II study of S-1 for metastatic pancreatic cancer. Cancer Chemother. Pharmacol. 61:615-21.

Okusaka T, Furuse J, Funakoshi A, loka T, Yamao K, Ohkawa S, Boku $\mathrm{N}$, Komatsu Y, Nakamori S, Iguchi H, Ito T, Nakagawa K, Nakachi K (2011). Phase II study of erlotinib plus gemcitabine in Japanese patients with unresectable pancreatic cancer. Cancer Sci. 102(2):425-31.

Palmer DH, Stocken DD, Hewitt $H$, Markham CE, Hassan AB, Johnson PJ, Buckels JA, Bramhall SR (2007). A randomized phase 2 trial of neoadjuvant chemotherapy in resectable pancreatic cancer: gemcitabine alone versus gemcitabine combined with cisplatin. Ann. Surg. Oncol. 14(7):2088-96.

Pelzer U, Stieler J, Roll L, Hilbig A, Dörken B, Riess H, Oettle H (2009). Second-line therapy in refractory pancreatic cancer. Results of a phase II study. Onkologie 32(3):99-102.

Pericay PC, Escudero EP, Bastús PR, Campos CJM, Esquerdo GG, Gallén CM, Alfaro GJ, Dotor NE, Pisa GA, Guasch JI, Saigí GE, ACROSS group (2011). Open-label trial on efficacy and security of treatment with gemcitabine and oral modulation with tegafur and levofolinic acid (GEMTG) in patients with advanced pancreatic cancer. Clin. Transl. Oncol. 13(1):61-6.

Peters GJ, Bergman AM, Ruiz van Haperen VW, Veerman G, Kuiper CM, Braakhuis BJ (1995). Interaction between cisplatin and Gemin vitro and in vivo. Semin. Oncol. 22:72-79.

Philip PA, Benedetti J, Corless CL, Wong R, O'Reilly EM, Flynn PJ, Rowland KM, Atkins JN, Mirtsching BC, Rivkin SE, Khorana AA, Goldman B, Fenoglio-Preiser CM, Abbruzzese JL, Blanke CD (2010). Phase III study comparing gemcitabine plus cetuximab versus gemcitabine in patients with advanced pancreatic adenocarcinoma: Southwest Oncology Group-directed intergroup trial S0205. J. Clin. Oncol. 28(22):3605-10.

Poplin E, Feng Y, Berlin J, Rothenberg ML, Hochster H, Mitchell E, Alberts S, O'Dwyer P, Haller D, Catalano P, Cella D, Benson AB 3rd. (2009). Phase III, randomized study of gemcitabine and oxaliplatin versus gemcitabine (fixed-dose rate infusion) compared with gemcitabine (30-minute infusion) in patients with pancreatic carcinoma E6201: a trial of the Eastern Cooperative Oncology Group. J. Clin. Oncol. 27(23):3778-85.

Ramanathan RK, Abbruzzese J, Dragovich T, Kirkpatrick L, Guillen JM, Baker AF, Pestano LA, Green S, Von Hoff DD (2011). A randomized phase II study of PX-12, an inhibitor of thioredoxin in patients with advanced cancer of the pancreas following progression after a gemcitabine-containing combination. Cancer Chemother. Pharmacol.
67(3):503-9.

Raymond E, Dahan L, Raoul JL, Bang YJ, Borbath I, Lombard-Bohas C, Valle J, Metrakos P, Smith D, Vinik A, Chen JS, Hörsch D, Hammel P, Wiedenmann B, Van Cutsem E, Patyna S, Lu DR, Blanckmeister C, Chao R, Ruszniewski P (2011). Sunitinib malate for the treatment of pancreatic neuroendocrine tumors.N. Engl. J. Med. 364(6):501-13.

Ridwelski K, Fahlke J, Kuhn R, Hribaschek A, Kettner E, Greiner C, Florschuetz A, Manger T, Wilhelm G, Klein H, Hahnfeld S, Lippert $\mathrm{H}$, Meyer $F$ (2006). Multicenter phase-I/II study using a combination of gemcitabine and docetaxel in metastasized and unresectable, locally advanced pancreatic carcinoma. Eur. J. Surg. Oncol. 32(3):297-302.

Roehrig S, Wein A, Albrecht H, Konturek PC, Reulbach U, Männlein G, Wolff K, Ostermeier N, Hohenberger W, Hahn EG, Boxberger F (2010). Palliative first-line treatment with weekly high-dose 5fluorouracil as $24 \mathrm{~h}$-infusion and gemcitabine in metastatic pancreatic cancer (UICC IV). Med. Sci. Monit. 16(3):124-131.

Rowinsky EK (2004). Targeting the molecular target of rapamycin (mammalian target of rapamycin). Curr. Opin. Oncol. 16:564-575.

Royal RE, Levy C, Turner K, Mathur A, Hughes M, Kammula US, Sherry RM, Topalian SL, Yang JC, Lowy I, Rosenberg SA (2010). Phase 2 trial of single agent Ipilimumab (anti-CTLA-4) for locally advanced or metastatic pancreatic adenocarcinoma. J. Immunother. 33(8):828-33.

Sahora K, Kuehrer I, Eisenhut A, Akan B, Koellblinger C, Goetzinger P, Teleky B, Jakesz R, Peck-Radosavljevic M, Ba'ssalamah A, Zielinski C, Gnant M (2011). NeoGemOx: Gemcitabine and oxaliplatin as neoadjuvant treatment for locally advanced, nonmetastasized pancreatic cancer. Surg. 149(3):311-20.

Saif MW, Oettle H, Vervenne WL, Thomas JP, Spitzer G, Visseren-Grul C, Enas N, Richards DA (2009). Randomized double-blind phase II trial comparing gemcitabine plus LY293111 versus gemcitabine plus placebo in advanced adenocarcinoma of the pancreas. Cancer J. 15(4):339-43.

Saif MW, Podoltsev NA, Rubin MS, Figueroa JA, Lee MY, Kwon J, Rowen E, Yu J, Kerr RO (2010). Phase II clinical trial of paclitaxel loaded polymeric micelle in patients with advanced pancreatic cancer. Cancer Invest. 28(2):186-94.

Shimizu K, Watanabe S, Watanabe S, Matsuda K, Suga T, Nakazawa S, Shiratori K (2009).Efficacy of oral administered superfine dispersed lentinan for advanced pancreatic cancer. Hepatogastroenterol. 56(89):240-4.

Stathopoulos GP, Syrigos K, Aravantinos G, Polyzos A, Papakotoulas P, Fountzilas G, Potamianou A, Ziras N, Boukovinas J, Varthalitis J, Androulakis N, Kotsakis A, Samonis G, Georgoulias V (2006). A multicenter phase III trial comparing irinotecan-gemcitabine (IG) with gemcitabine $(G)$ monotherapy as first-line treatment in patients with locally advanced or metastatic pancreatic cancer. Br. J. Cancer. 95(5):587-92.

Stathopoulos GP, Syrigos K, Polyzos A, Fountzilas G, Rigatos SK, Ziras N, Potamiannou A, Tsiakopoulos I, Androulakis N, Aravantinos G, Athanasiadis A, Papakotoulas P, Georgoulias V (2004). Front-line treatment of inoperable or metastatic pancreatic cancer with gemcitabine and capecitabine: An intergroup, multicenter, phase II study. Ann. Oncol. 15:224-229.

Sudo K, Yamaguchi T, Nakamura K, Denda T, Hara T, Ishihara T, Yokosuka O (2011). Phase II study of $S-1$ in patients with gemcitabine-resistant advanced pancreatic cancer. Cancer Chemother. Pharmacol. 67(2):249-54.

Taïeb J, Lecomte T, Aparicio T, Asnacios A, Mansourbakht T, Artru P, Fallik D, Spano JP, Landi B, Lledo G, Desrame J (2007). FOLFIRI.3, a new regimen combining 5 -fluorouracil, folinic acid and irinotecan, for advanced pancreatic cancer: results of an Association des Gastro-Enterologues Oncologues (Gastroenterologist Oncologist Association) multicenter phase II study. Ann. Oncol. 18(3):498-503.

Ueda S, Ogata S, Tsuda H, Kawarabayashi N, Kimura M, Sugiura Y, Tamai S, Matsubara O, Hatsuse K, Mochizuki H (2004). The correlation between cytoplasmic overexpression of epidermal growth factor receptor and tumor aggressiveness:poor prognosis in patients with pancreatic ductal adenocarcinoma. Pancreas 29:1-8.

Ueno H, Kosuge T, Matsuyama Y, Yamamoto J, Nakao A, Egawa S, Doi R, Monden M, Hatori T, Tanaka M, Shimada M, Kanemitsu K 
(2009). A randomised phase III trial comparing gemcitabine with surgery-only in patients with resected pancreatic cancer: Japanese Study Group of Adjuvant Therapy for Pancreatic Cancer. Br. J. Cancer. 101(6):908-15.

Ueno H, Okusaka T, Funakoshi A, Ishii H, Yamao K, Ishikawa O, Ohkawa S, Saitoh S (2007). A phase II study of weekly irinotecan as first-line therapy for patients with metastatic pancreatic cancer. Cancer Chemother. Pharmacol. 59(4):447-54.

Van Cutsem E, van de Velde $H$, Karasek P, Oettle H, Vervenne WL, Szawlowski A, Schoffski P, Post S, Verslype C, Neumann H, Safran H, Humblet Y, Perez Ruixo J, Ma Y, Von Hoff D (2004). Phase III trial of gemcitabine plus tipifarnib compared with gemcitabine plus placebo in advanced pancreatic cancer. J. Clin. Oncol. 22(8):1430-8.

Van Cutsem E, Vervenne WL, Bennouna J, Humblet Y, Gill S, Van Laethem JL, Verslype C, Scheithauer W, Shang A, Cosaert J, Moore MJ (2009). Phase III trial of bevacizumab in combination with gemcitabine and erlotinib in patients with metastatic pancreatic cancer. J. Clin. Oncol. 27(13):2231-7.

Wasser SP (2002). Medicinal mushrooms as a source of antitumor and immunomodulating polysaccharides. Appl. Microbiol. Biotechnol. 60(3):258-74.

Yanagimoto $\mathrm{H}$, Shiomi $\mathrm{H}$, Satoi S, Mine T, Toyokawa H, Yamamoto T, Tani T, Yamada A, Kwon AH, Komatsu N, Itoh K, Noguchi M (2010). A phase II study of personalized peptide vaccination combined with gemcitabine for non-resectable pancreatic cancer patients. Oncol. Rep. 24(3):795-801.
Yao JC, Shah MH, Ito T, Bohas CL, Wolin EM, Van Cutsem E, Hobday TJ, Okusaka T, Capdevila J, de Vries EG, Tomassetti P, Pavel ME, Hoosen S, Haas T, Lincy J, Lebwohl D, Oberg K (2011). Everolimus for advanced pancreatic neuroendocrine tumors. N. Engl. J. Med. 364(6):514-23.

Yi SY, Park YS, Kim HS, Jun HJ, Kim KH, Chang MH, Park MJ, Uhm JE, Lee J, Park SH, Park JO, Lee JK, Lee KT, Lim HY, Kang WK (2009). Irinotecan monotherapy as second-line treatment in advanced pancreatic cancer. Cancer Chemother. Pharmacol. 63(6):1141-5.

Yoo C, Hwang JY, Kim JE, Kim TW, Lee JS, Park DH, Lee SS, Seo DW, Lee SK, Kim MH, Han DJ, Kim SC, Lee JL (2009). A randomised phase II study of modified FOLFIRI.3 vs. modified FOLFOX as second-line therapy in patients with gemcitabinerefractory advanced pancreatic cancer. Br. J. Cancer 101(10):165863. 